\title{
Asymmetric Intermolecular Heck Reaction of Aryl Halides
}

Chunlin Wu, Jianrong (Steve) Zhou

Division of Chemistry and Biological Chemistry,

School of Physical and Mathematical Sciences, Nanyang Technological University,

21 Nanyang Link, Singapore 637371

E-mail:jrzhou@ntu.edu.sg

Supporting Information: NMR spectra 
WCL3087-A-2 1HNMR BBF01 CDCl3 2013-8-20

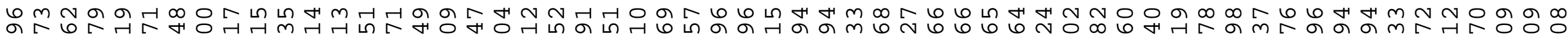
N ดீ N
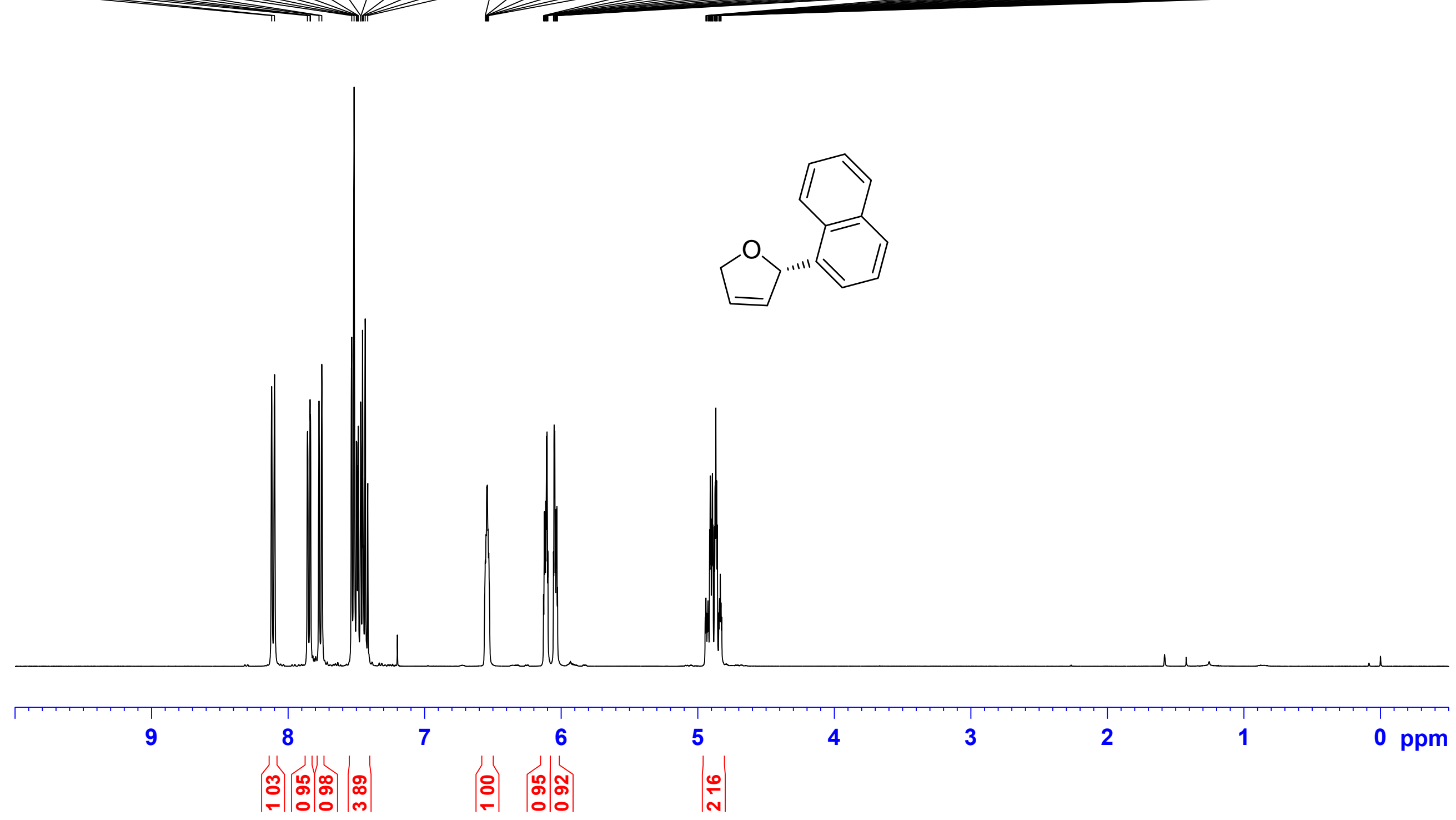


$$
\sqrt{111}
$$


WCL3087-C-1H, BBF01 $07-09-2013$

ஓ m

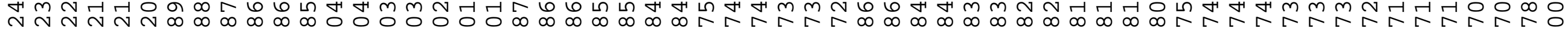

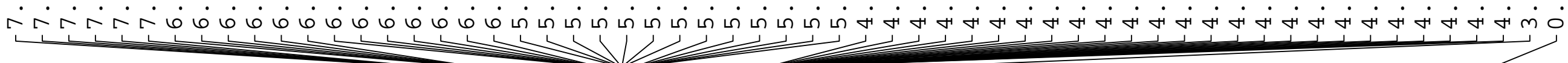

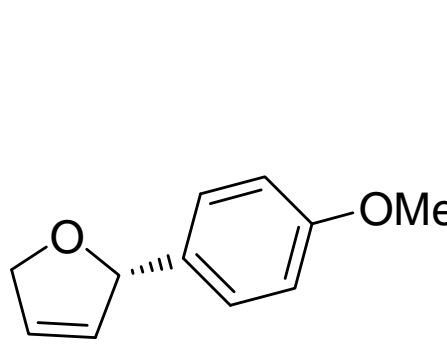

M Wh

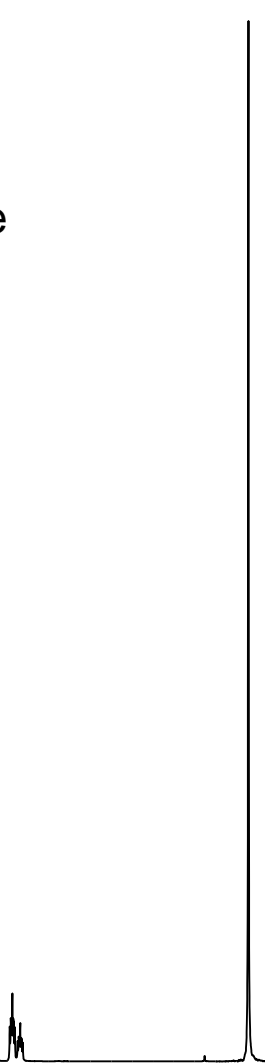

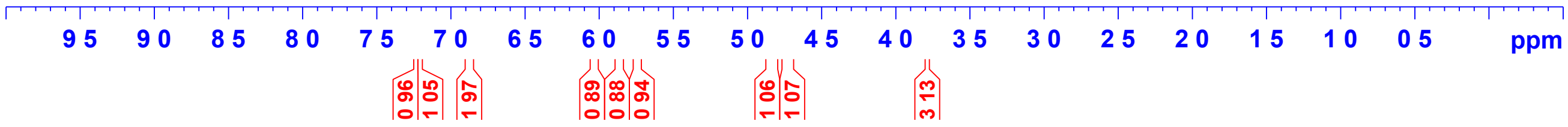


m m 슬요 m m NHH A $\wedge$ ก
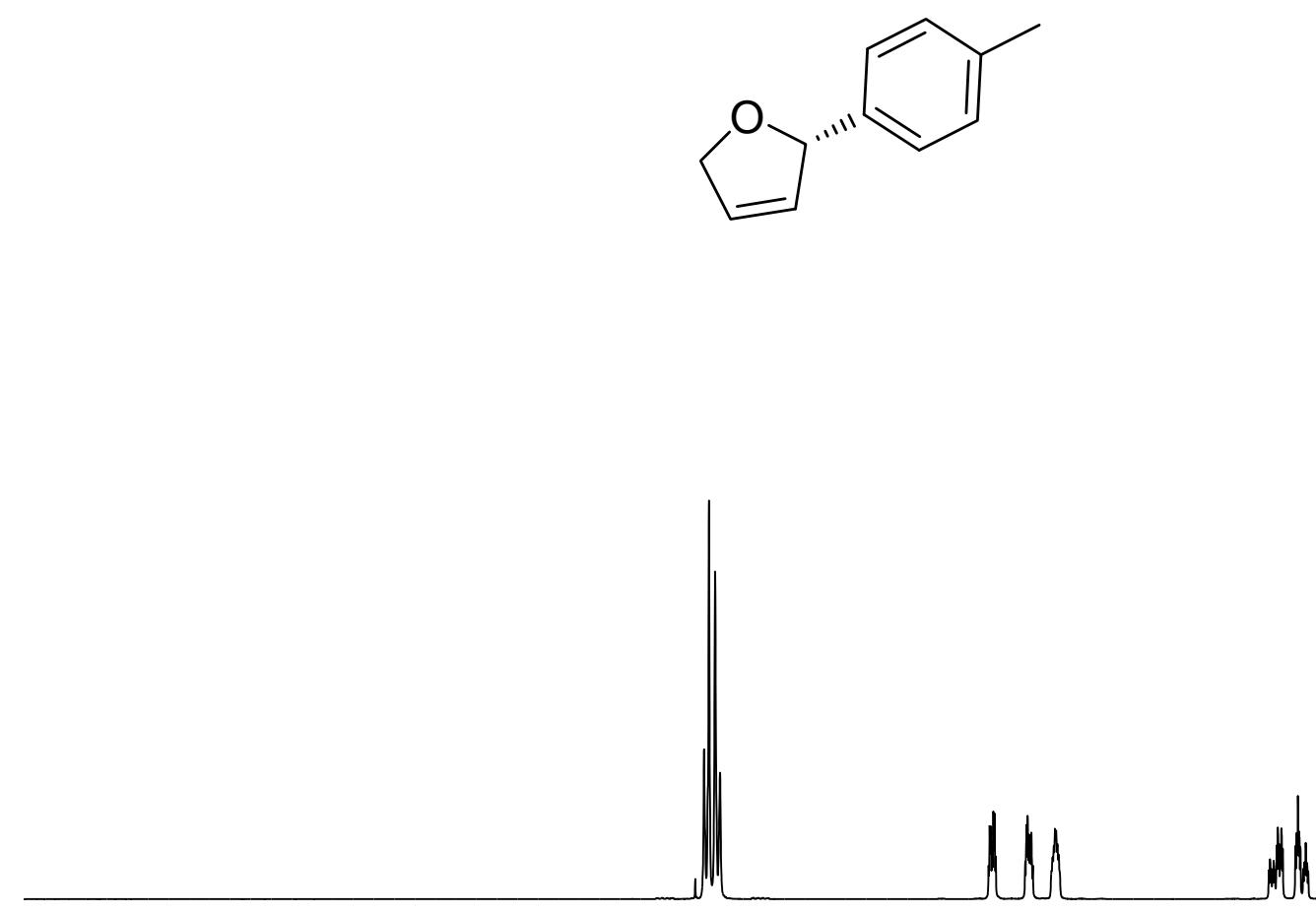

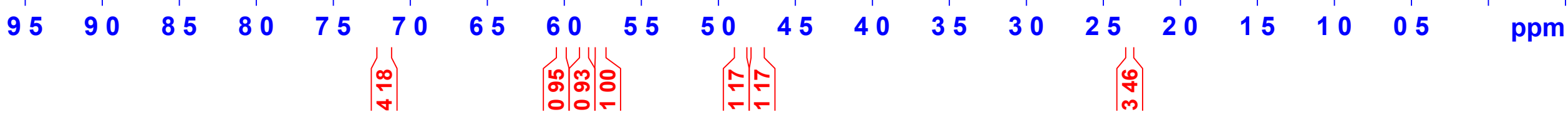


WCL3088B-1H, BBF01 24-09-2013

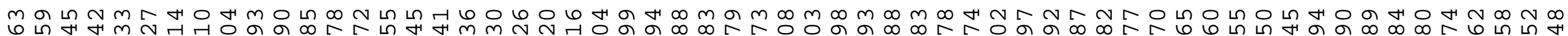
m ल m m

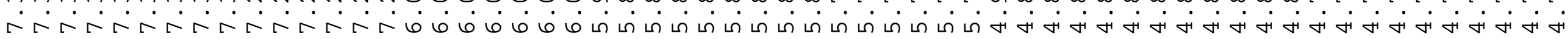
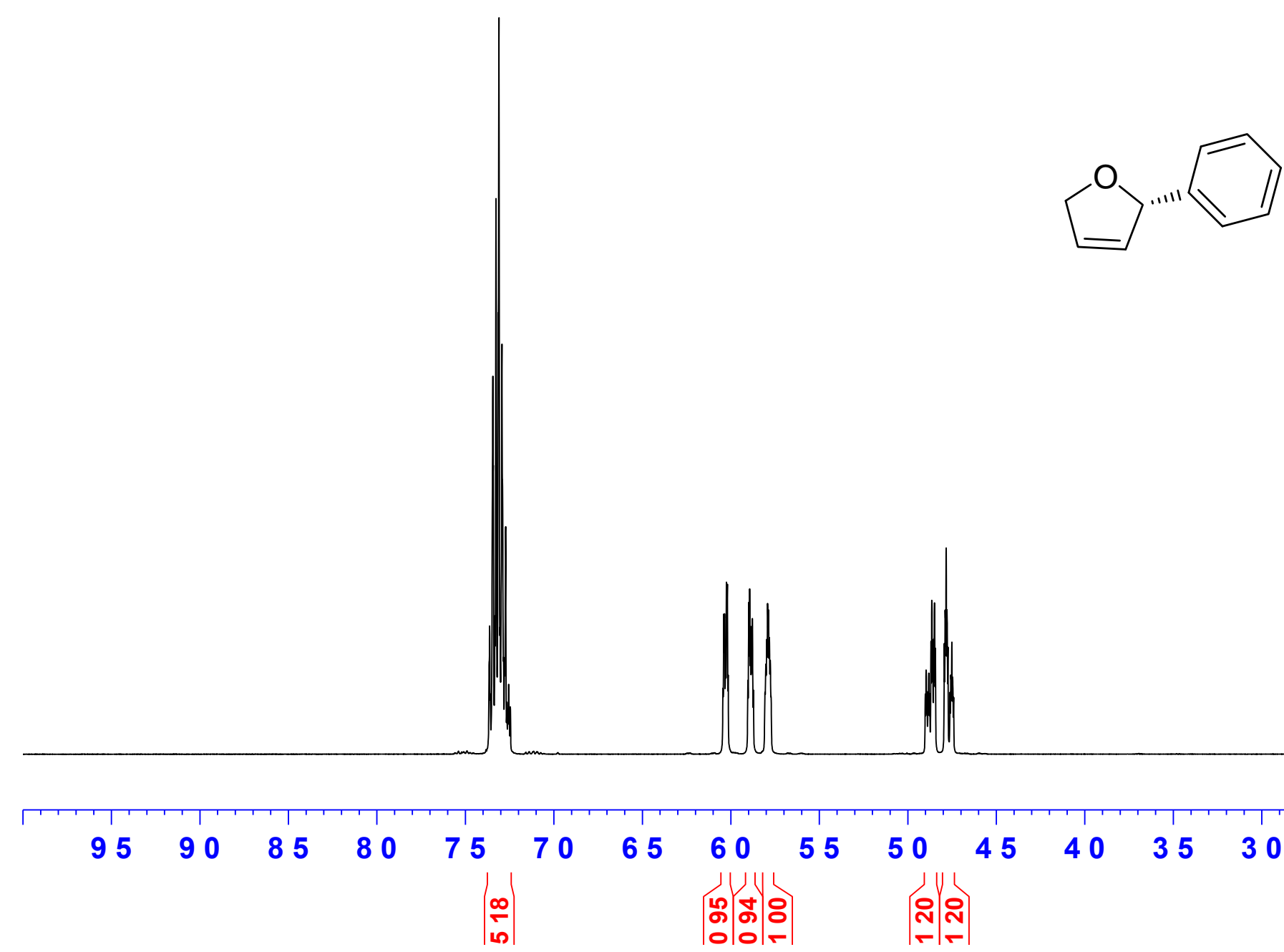
WCL3088-D-1H 1HNMR BBF01 CDCl3 2013-8-20

m m N N N N rírírí

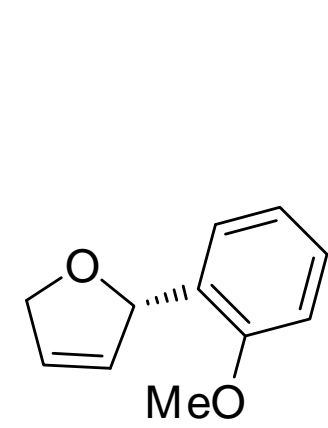

M

ith

Nh

$95 \quad 90 \quad 85 \quad 80 \quad 75 \quad 70$

65

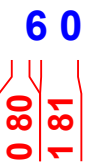

55

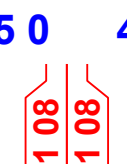

4540

35

30

25

20

5


WCL3089-D-1H, av500, 22-0ct-2013

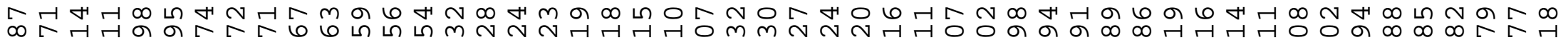

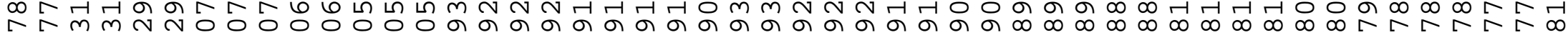

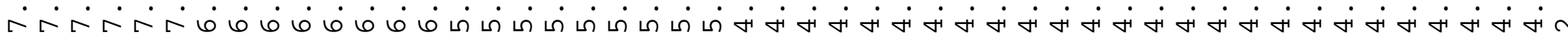
(n)
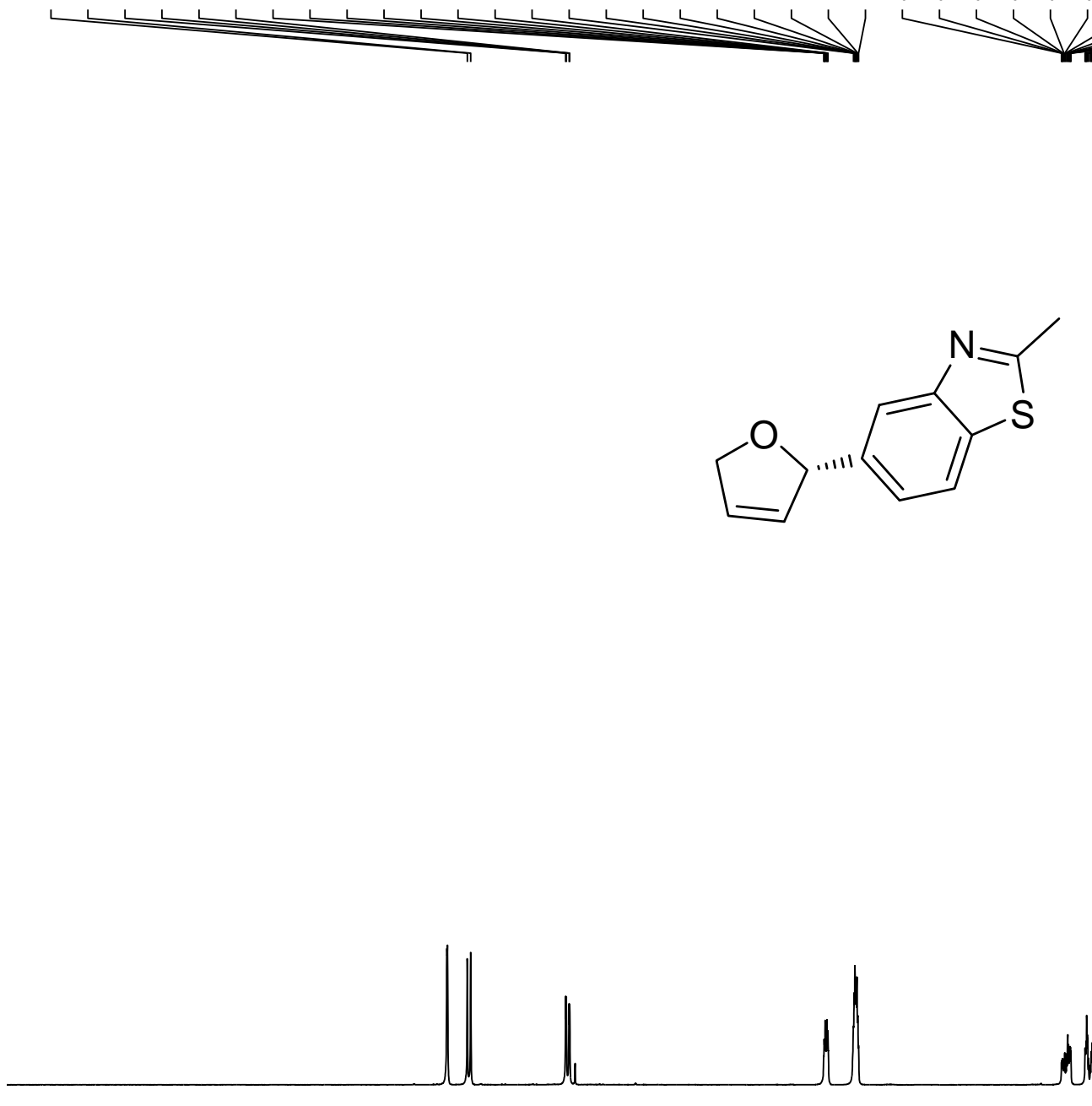
WCL3089-D-13C, BBF1, 09-0CT-2013

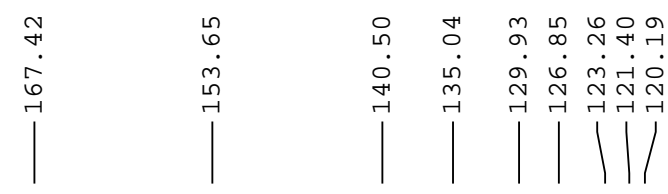

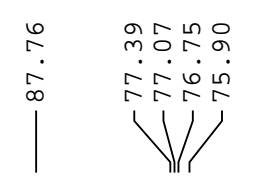

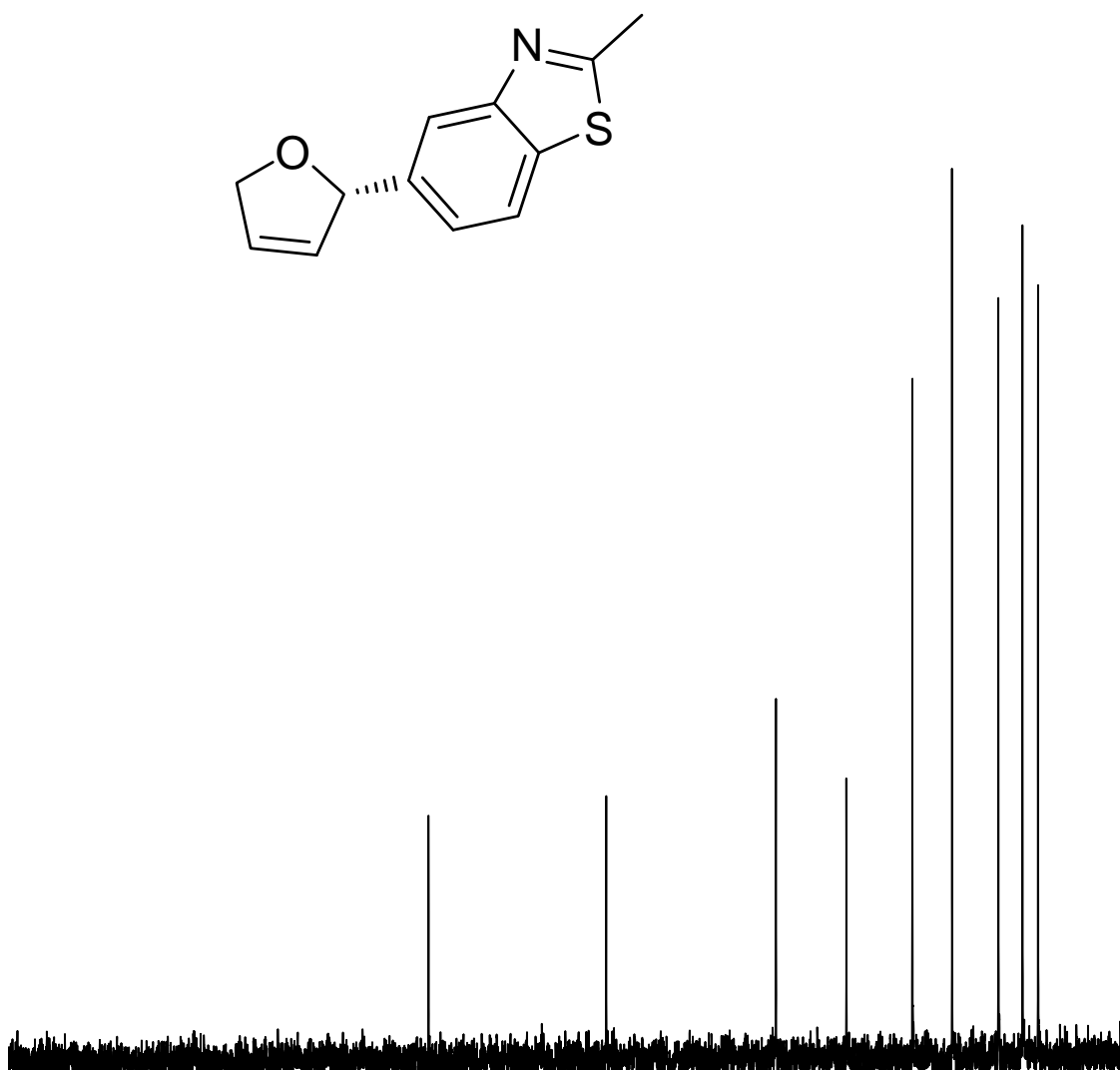


WCL4023-B-1H, av500, 22-0ct-2013

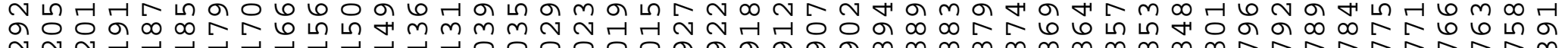

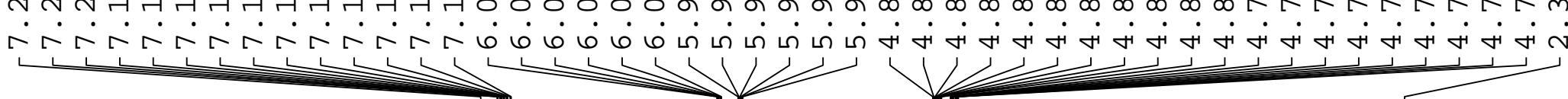<smiles>Cc1ccccc1[C@H]1C=CCO1</smiles>

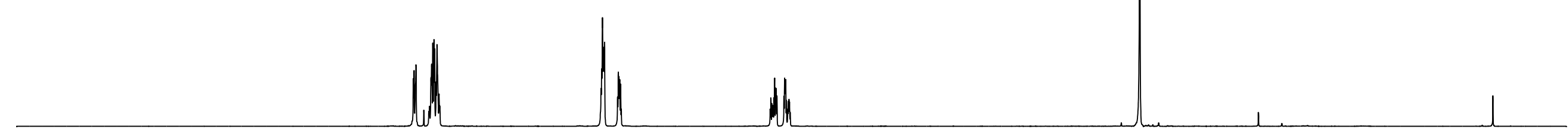

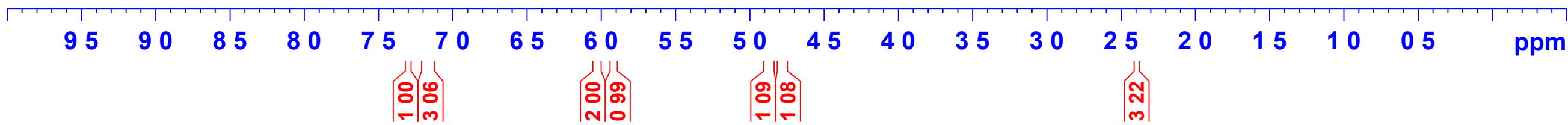


WCL4039--A-1H 1HNMR BBF01 CDCl3 2013-8-31

O구에 足

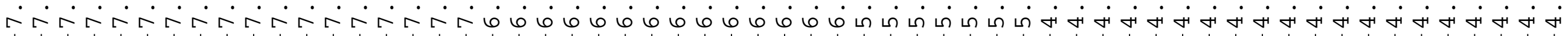
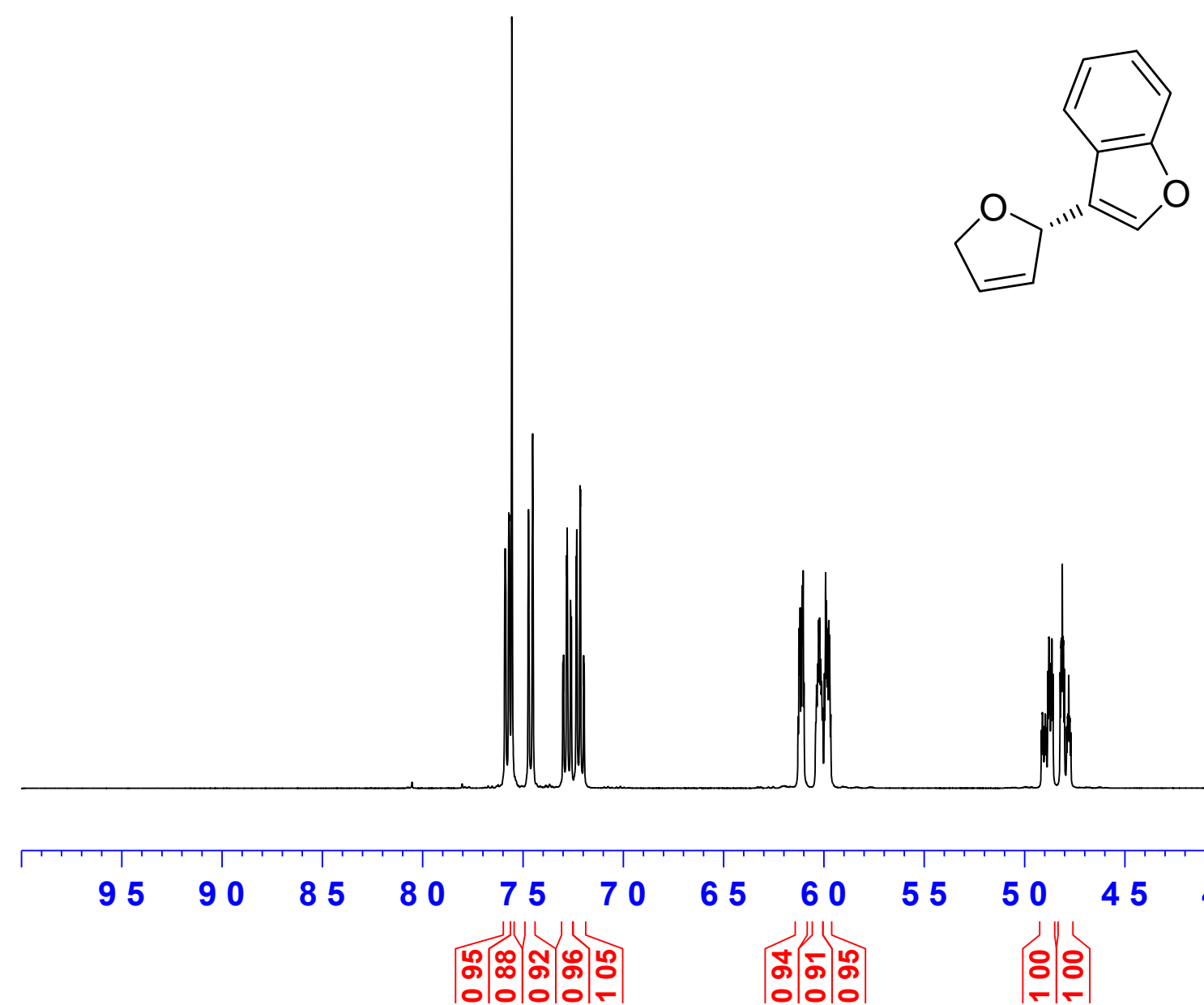

45

40

35

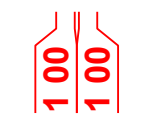


WCL4039--A 13CNMR BBF01 CDCl3 2013-8-31

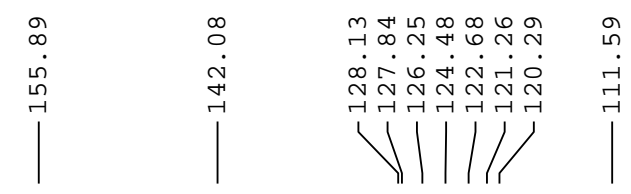

유ㅇㅛㅠ웡

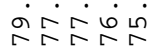

MV

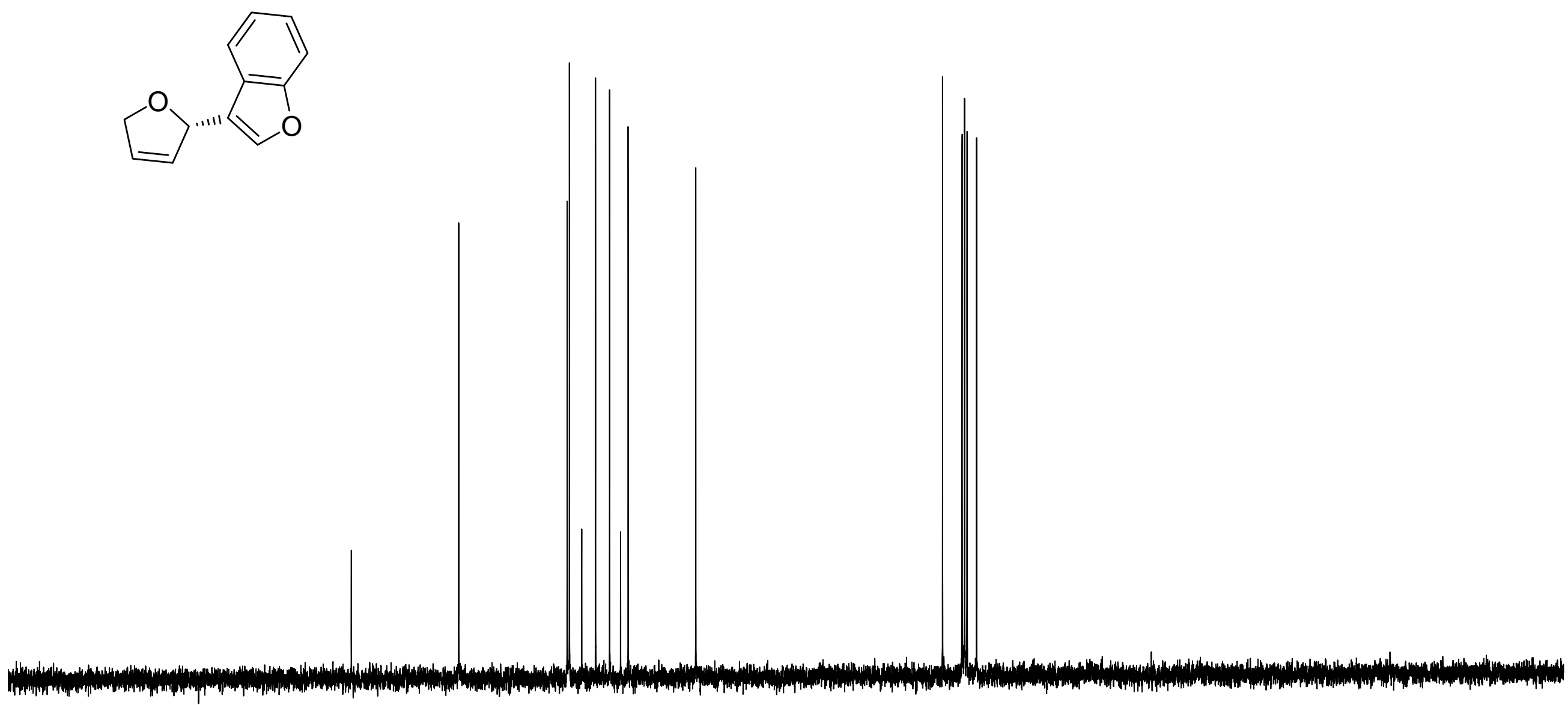


WCL4039-B-1H 1HNMR BBF01 CDC13 2013-8-31

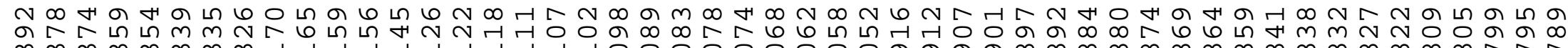

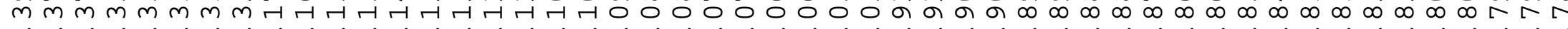

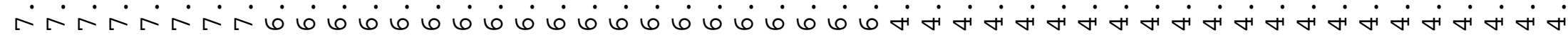
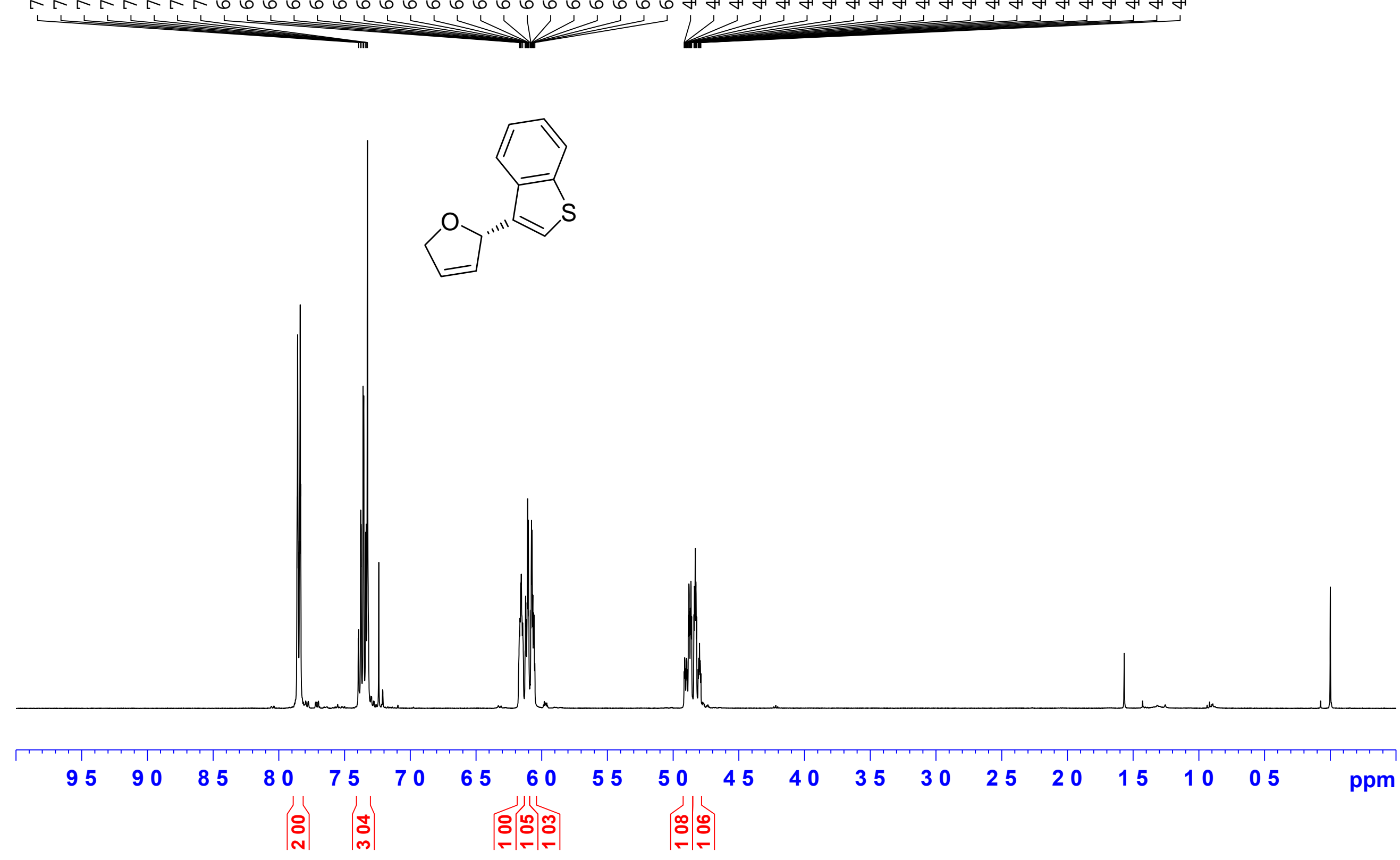
WCL4039-B 13CNMR BBF01 CDCl3 2013-8-31

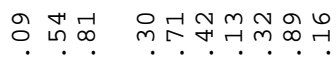

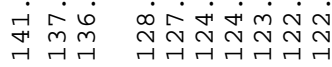

吕 융종

$1 / 1$

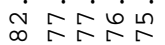

V/

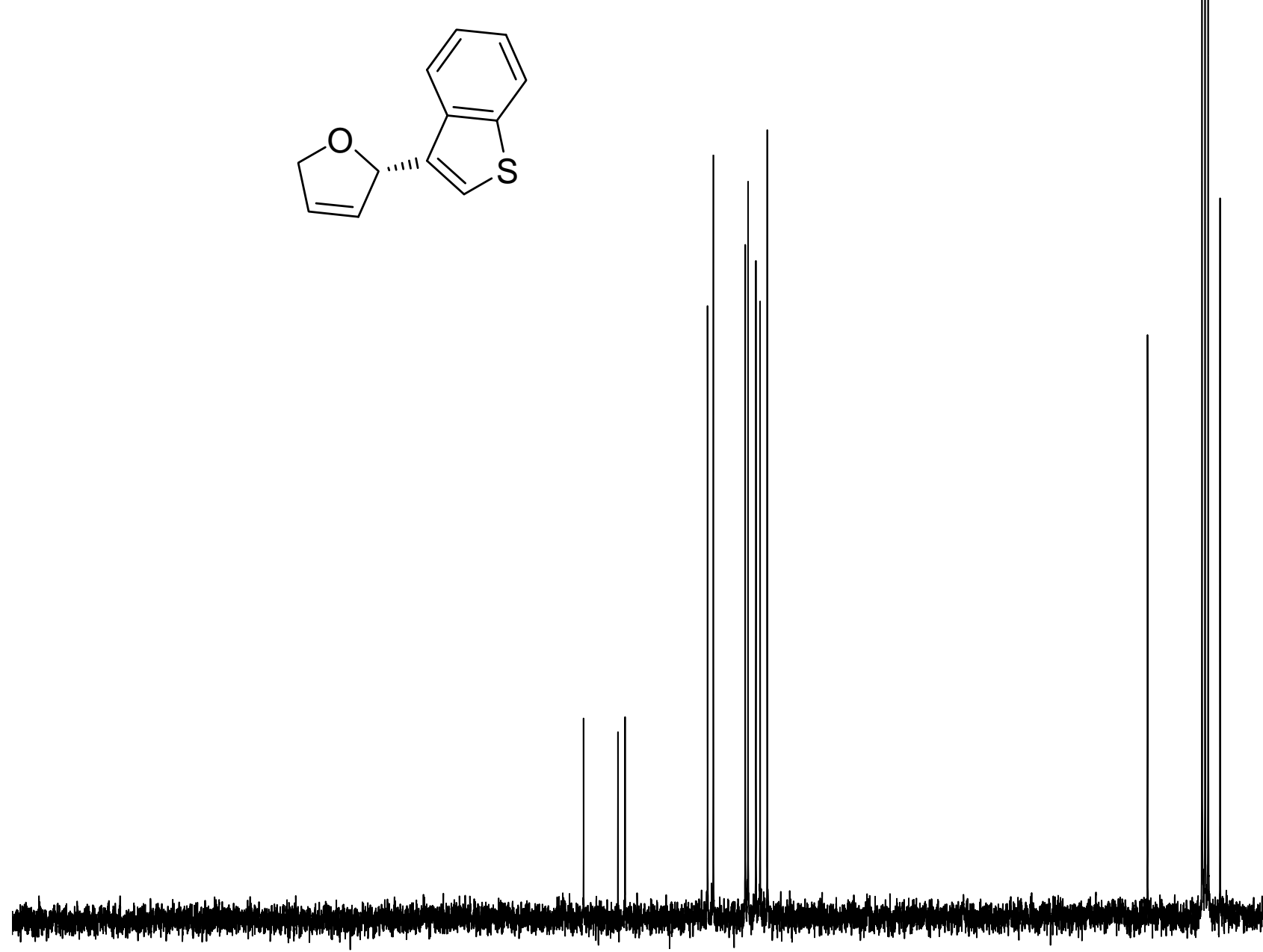

(1) 


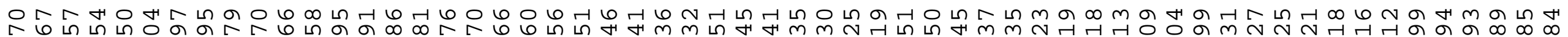

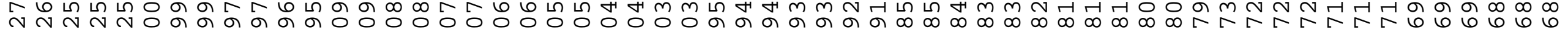
rírír

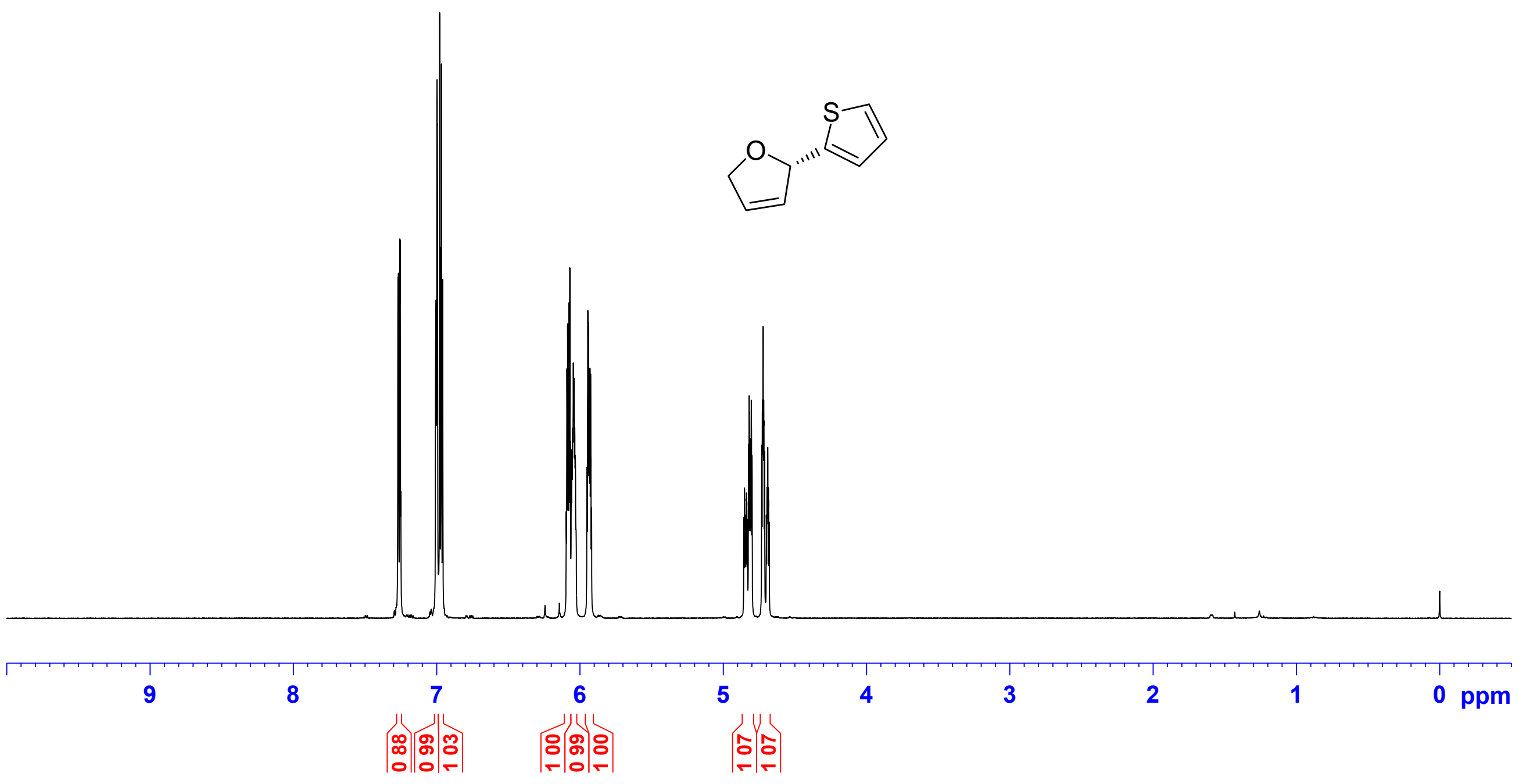


WCL4044-A 13CNMR BBF01 CDCl3 2013-8-31

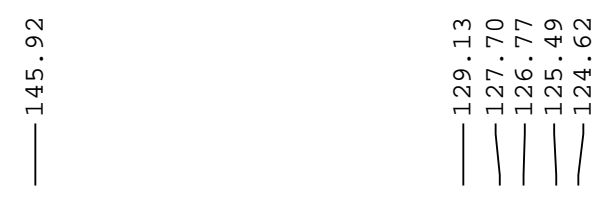

$\left.\right|_{\substack{\infty \\ \infty}} ^{\infty}$

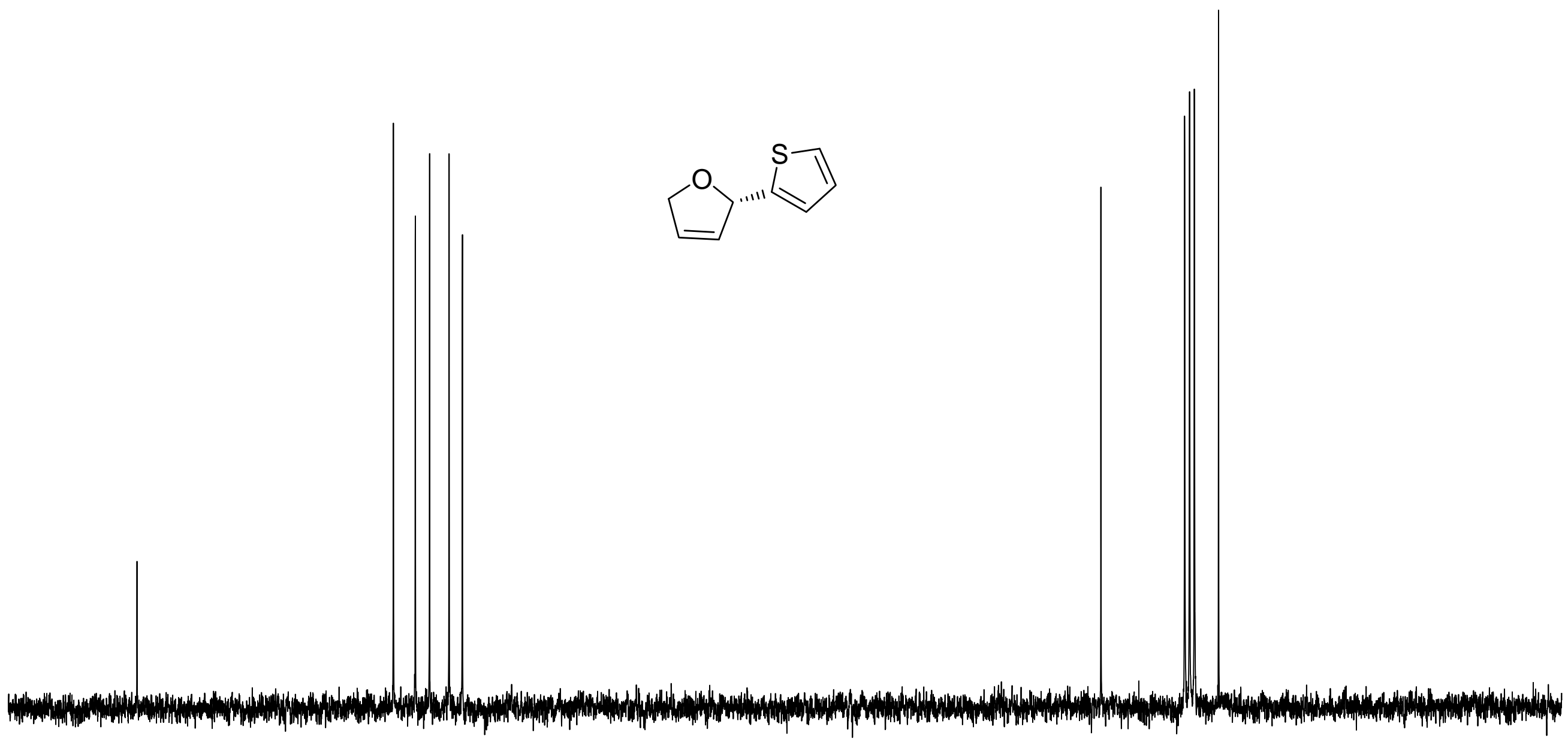

$\begin{array}{lllllllllllllllllllllll}150 & 145 & 140 & 135 & 130 & 125 & 120 & 115 & 110 & 105 & 100 & 95 & 90 & 85 & 80 & 75 & 70 & 65 & 60 & \mathrm{ppm}\end{array}$


WCL4048-A-1H, BBF01 18-09-2013

ํㅛ mं் N

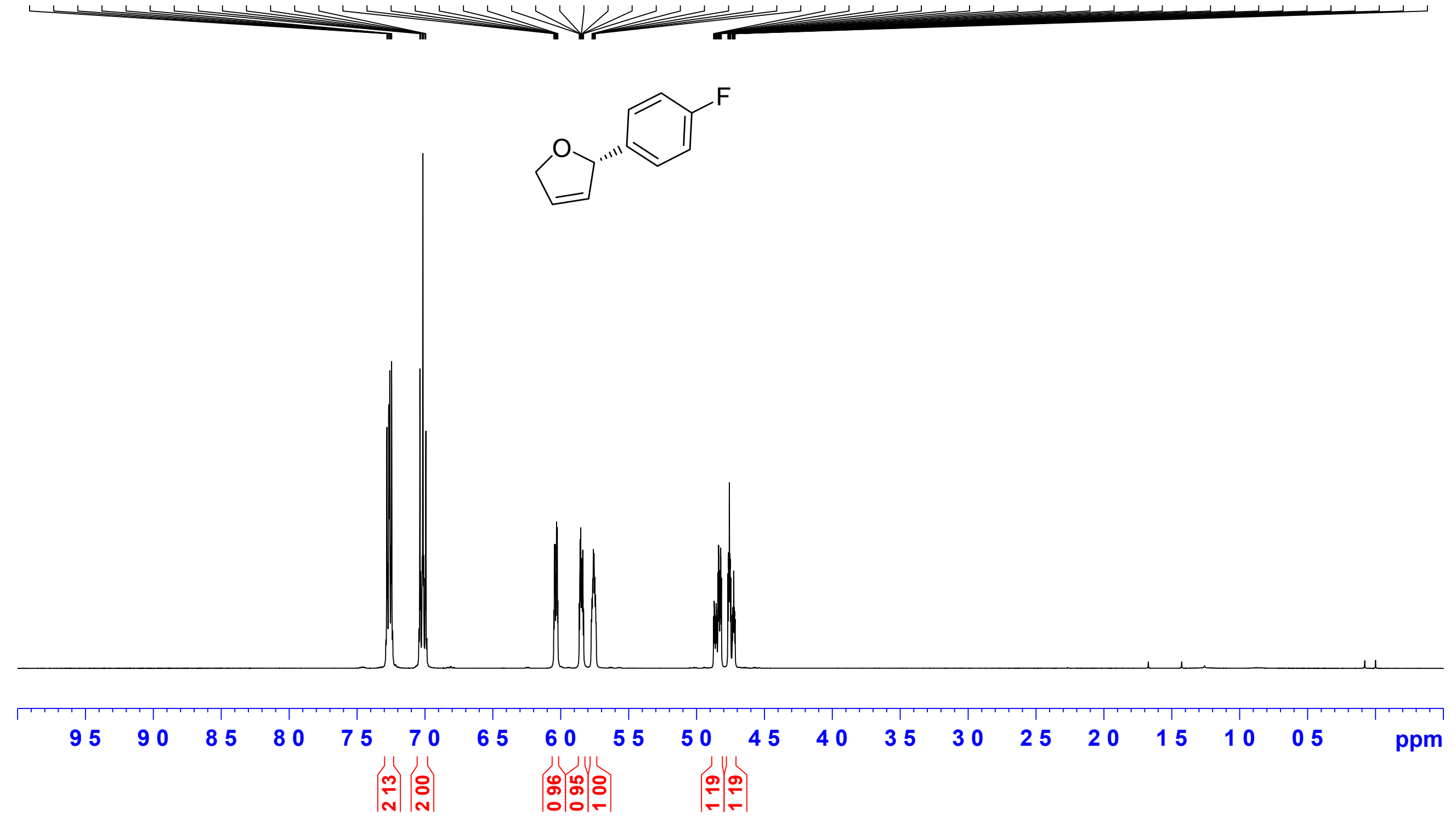


WCL4050-B 1HNMR BBF01 CDC13 2013-8-31

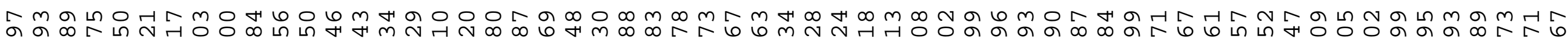
ब्लm

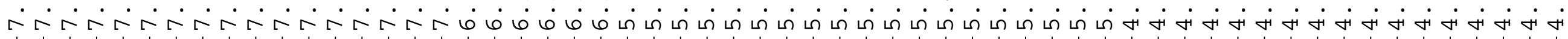

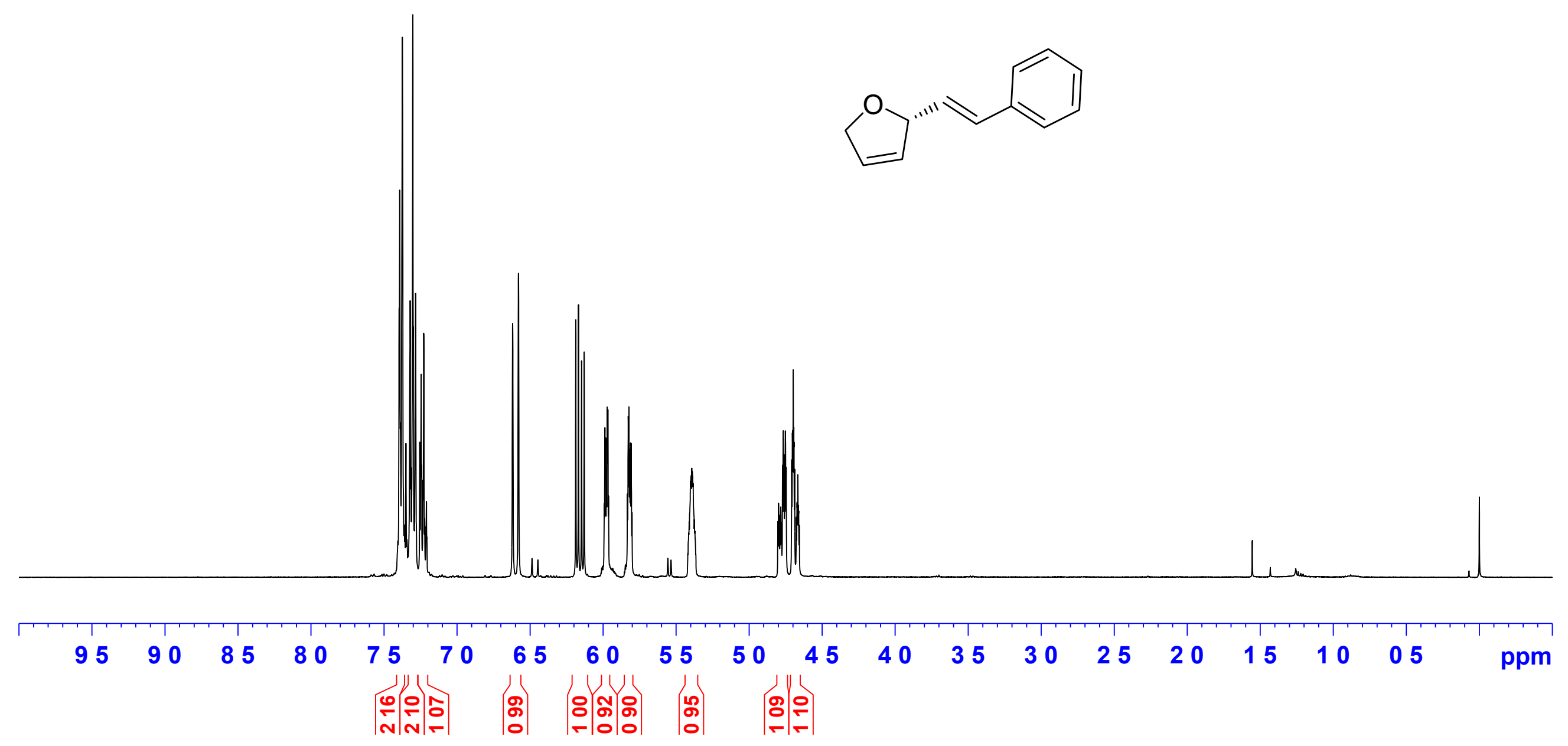


WCL4050-B 13CNMR BBF01 CDCl3 2013-8-31
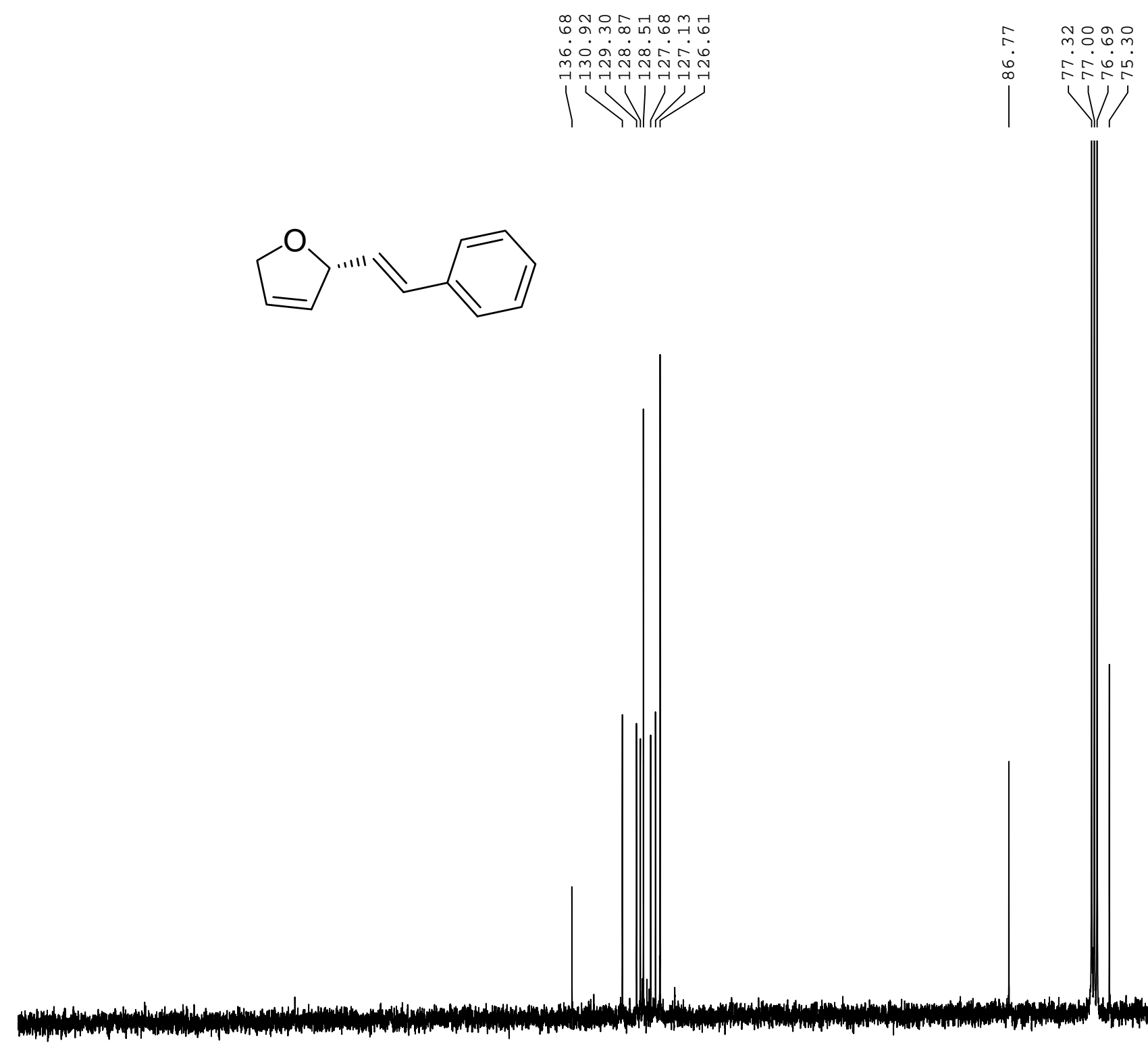

190180 
WCL3097-A-2 1HNMR BBF01 CDCl3 2013-8-15

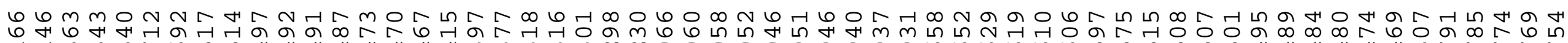

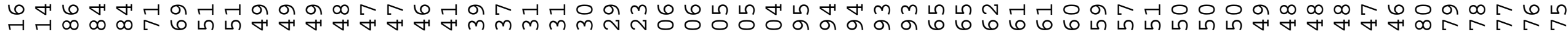

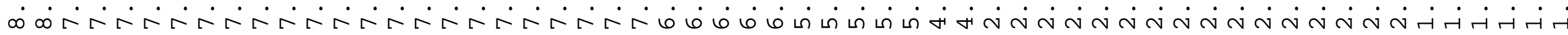
linn
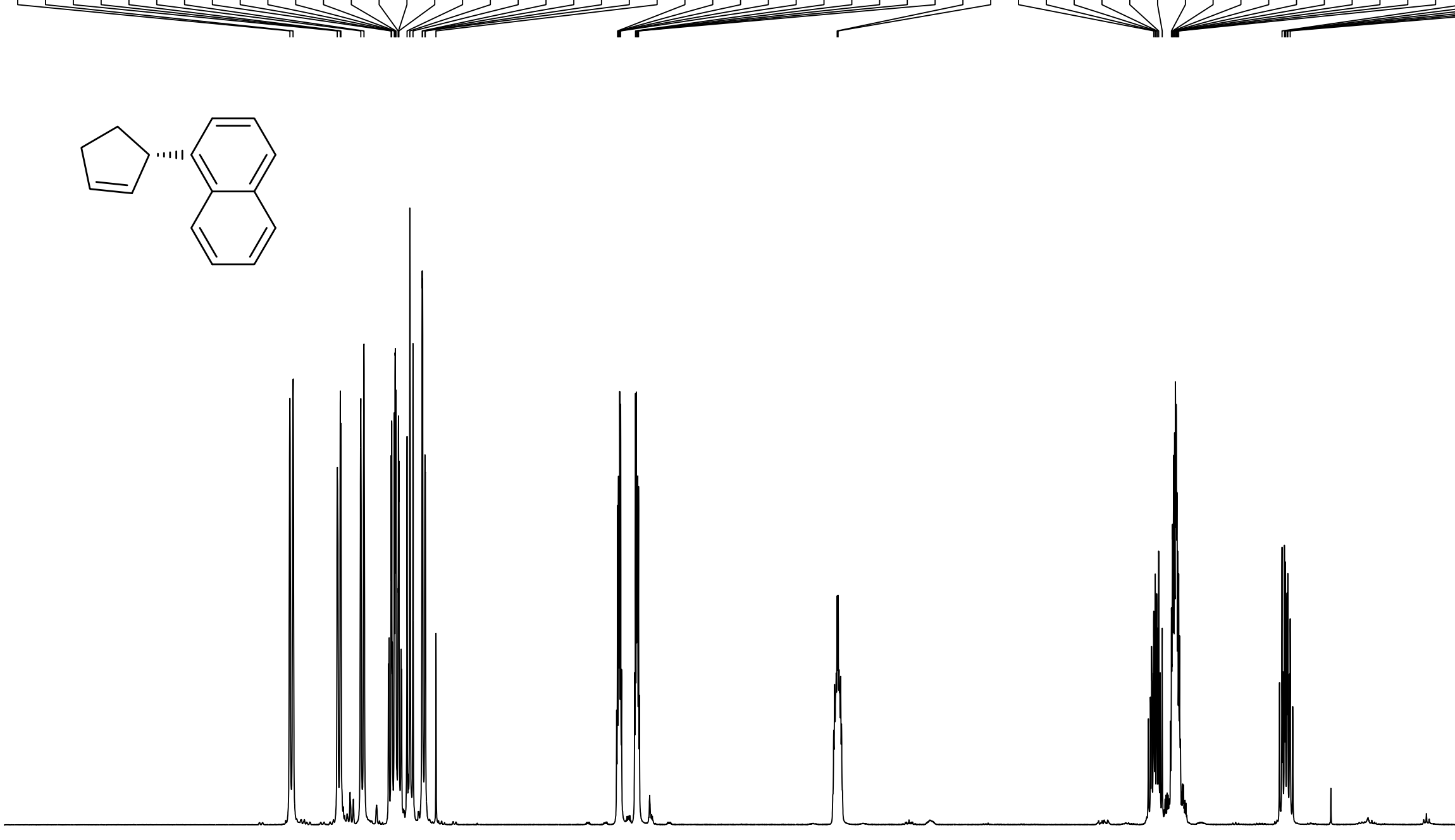


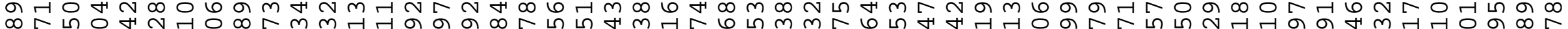

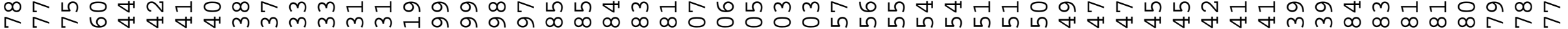

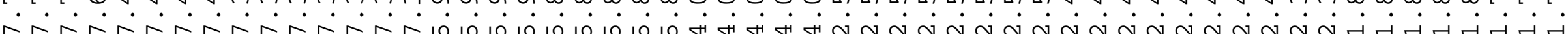

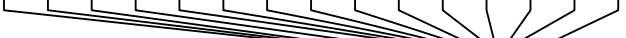
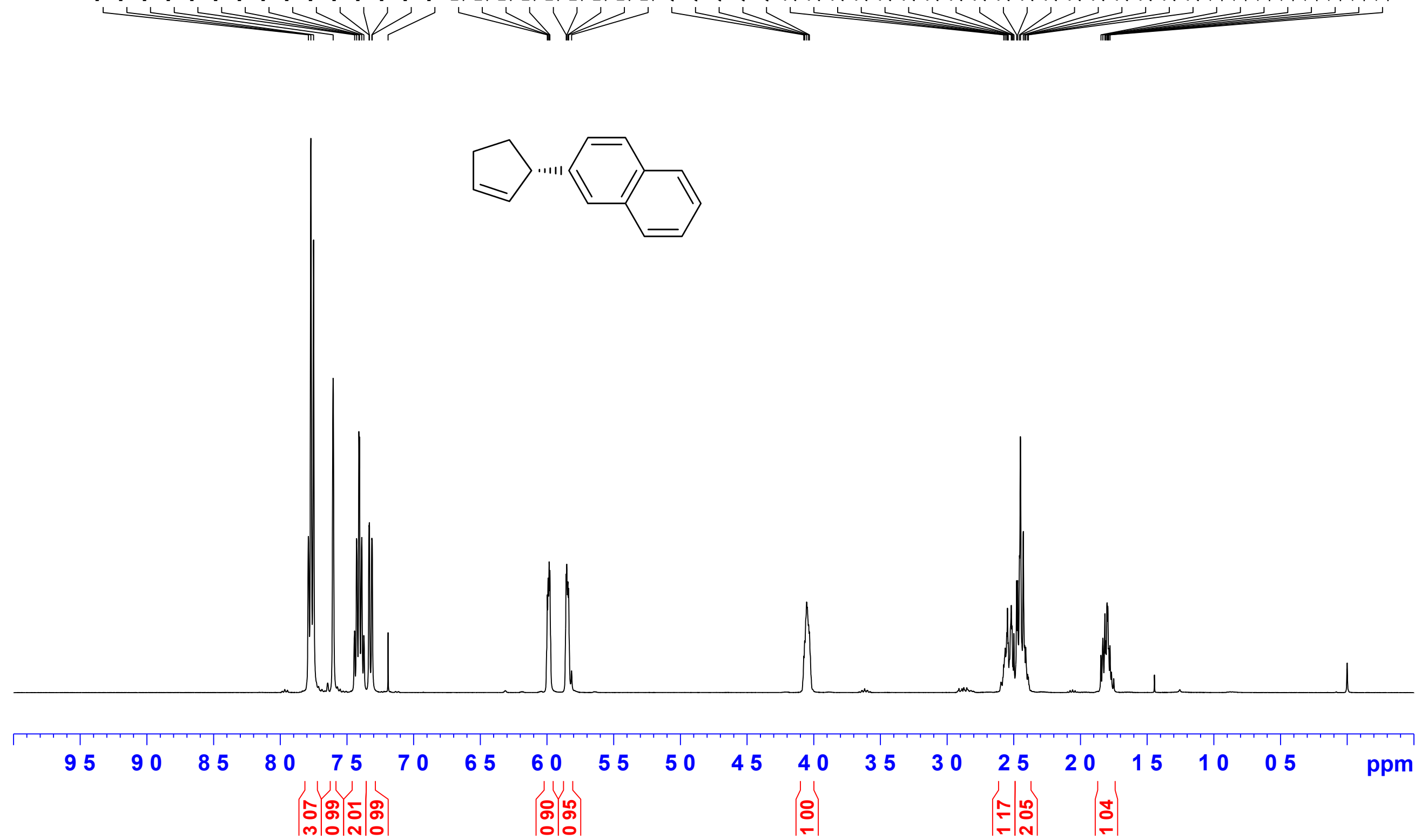
WCL3097-C-2 1HNMR BBF01 CDCl3 2013-8-15

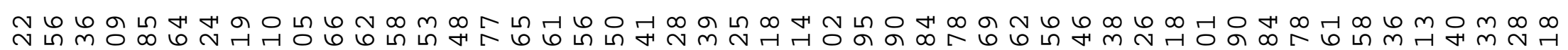

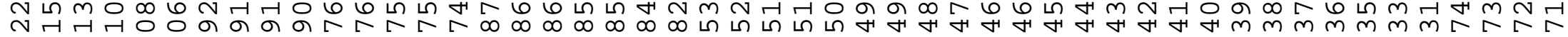
N M

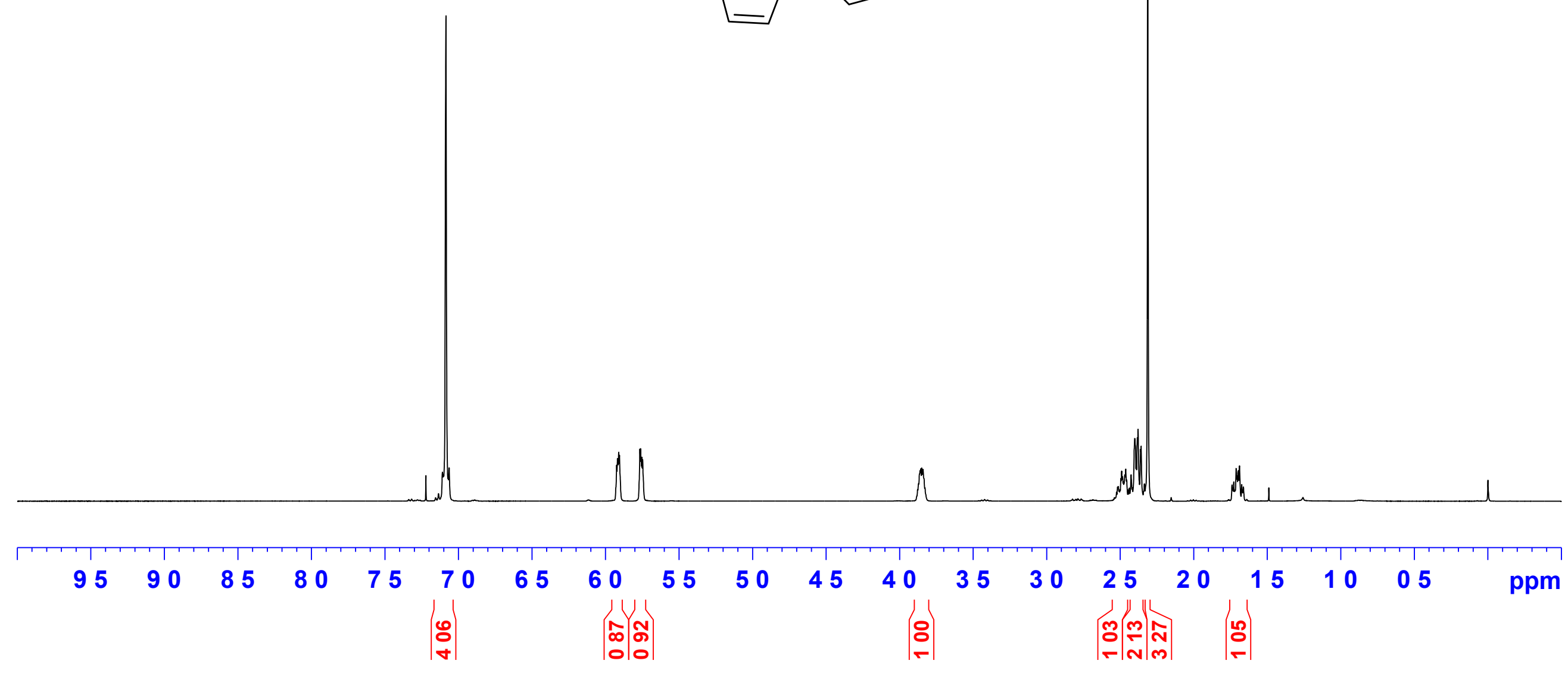


WCL3097-C 13CNMR BBF01 CDCl3 2013-8-15
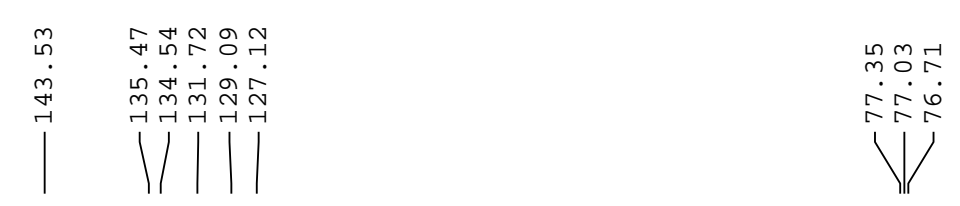

$\mid$
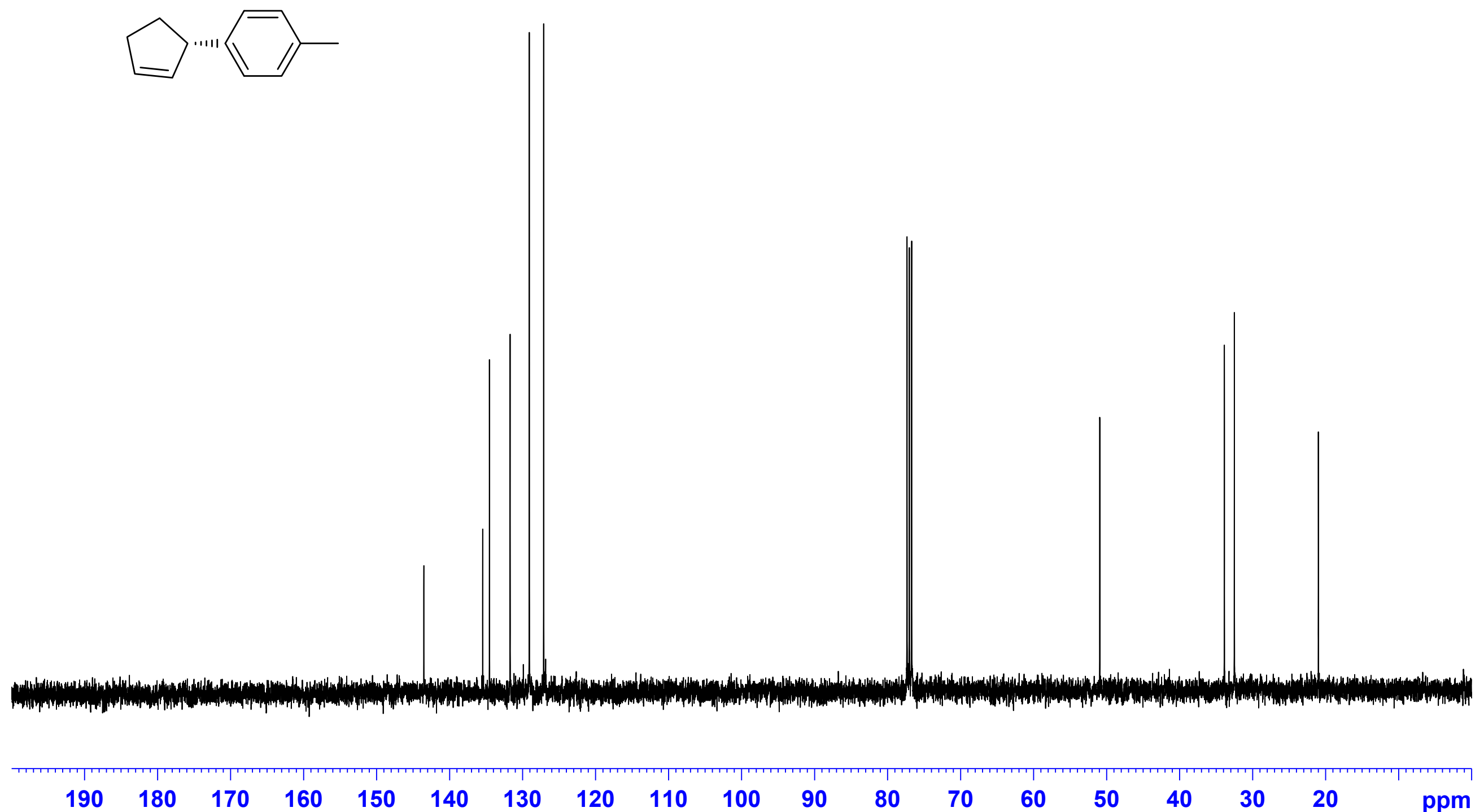
WCL3097-D-1H, BBF01 26-09-2013

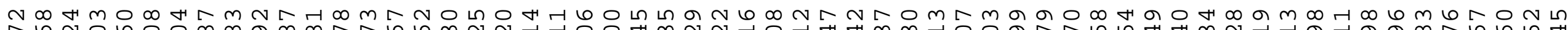

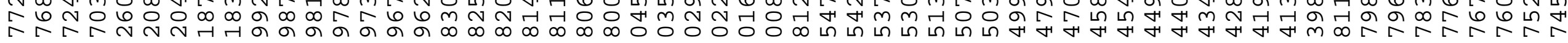

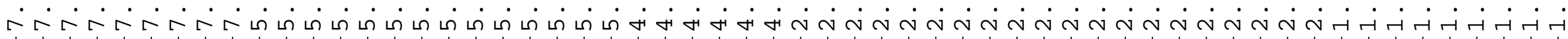<smiles>Cc1nc2cc([C@H]3C=CCC3)ccc2s1</smiles>
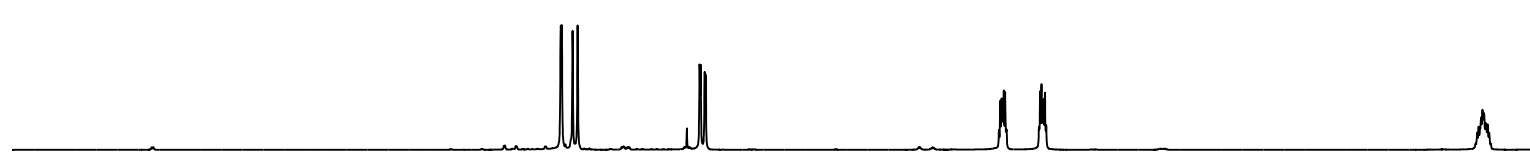

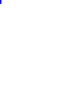

6

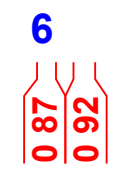

3

$\left|\begin{array}{c}\hat{N} \\ \text { N }\end{array}\right|\left|\begin{array}{l}0 \\ N \\ m\end{array}\right|$ 
WCL3097-H-2 1HNMR BBF01 CDCl3 2013-8-15

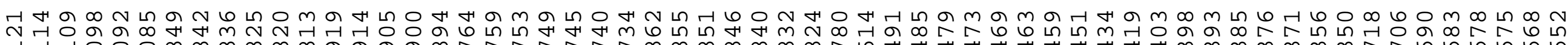

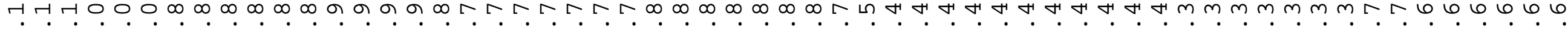
rír II<smiles>COc1ccc([C@H]2C=CCC2)cc1</smiles>
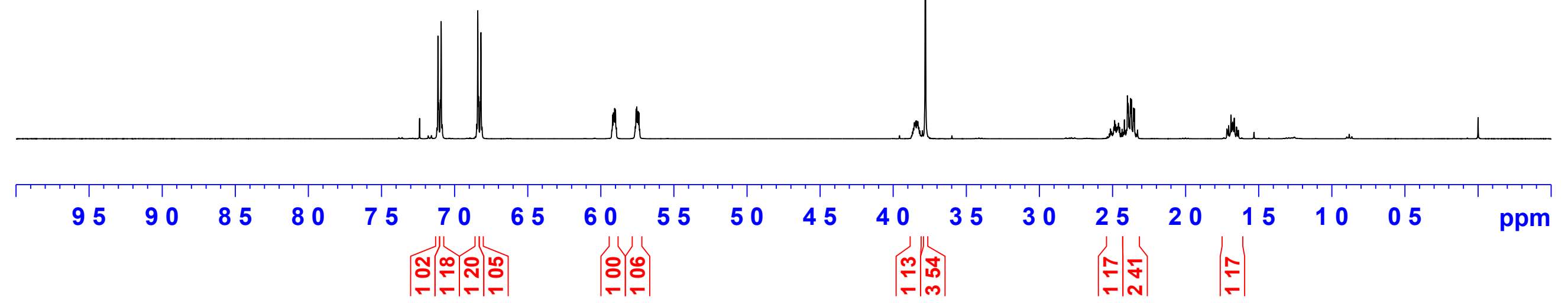
WCL3097-I-2 1HNMR BBF01 CDCl3 2013-8-16

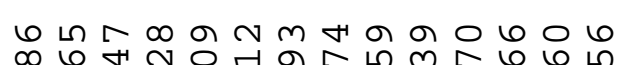

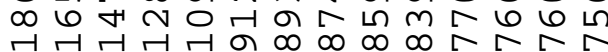
ن. 1

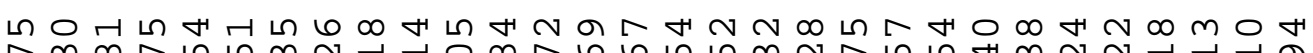
స

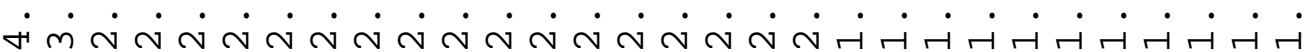
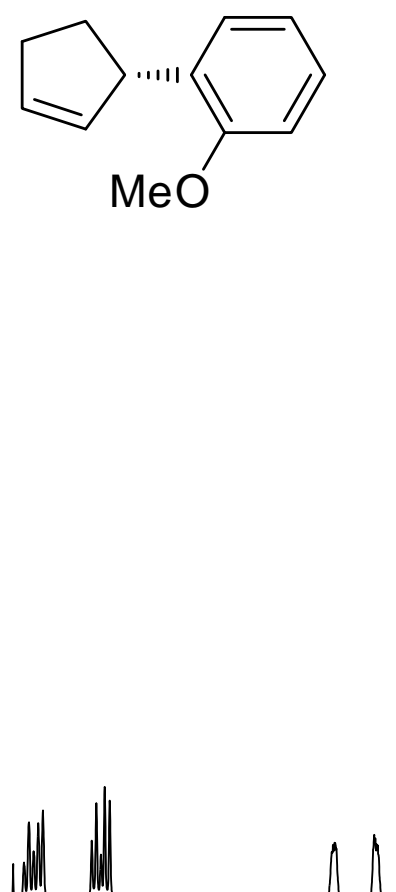

M

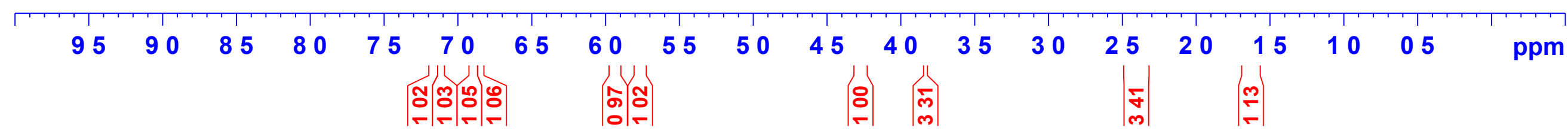


WCL3123-D1HNMR BBF01 CDC13 2013-8-14

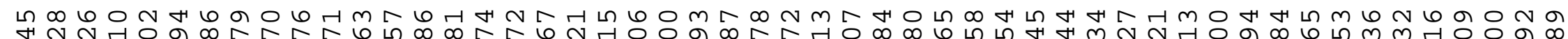
H H H

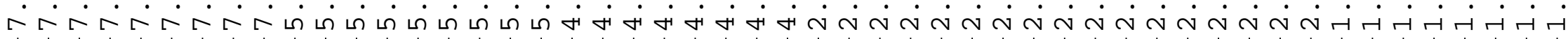
$\longrightarrow$
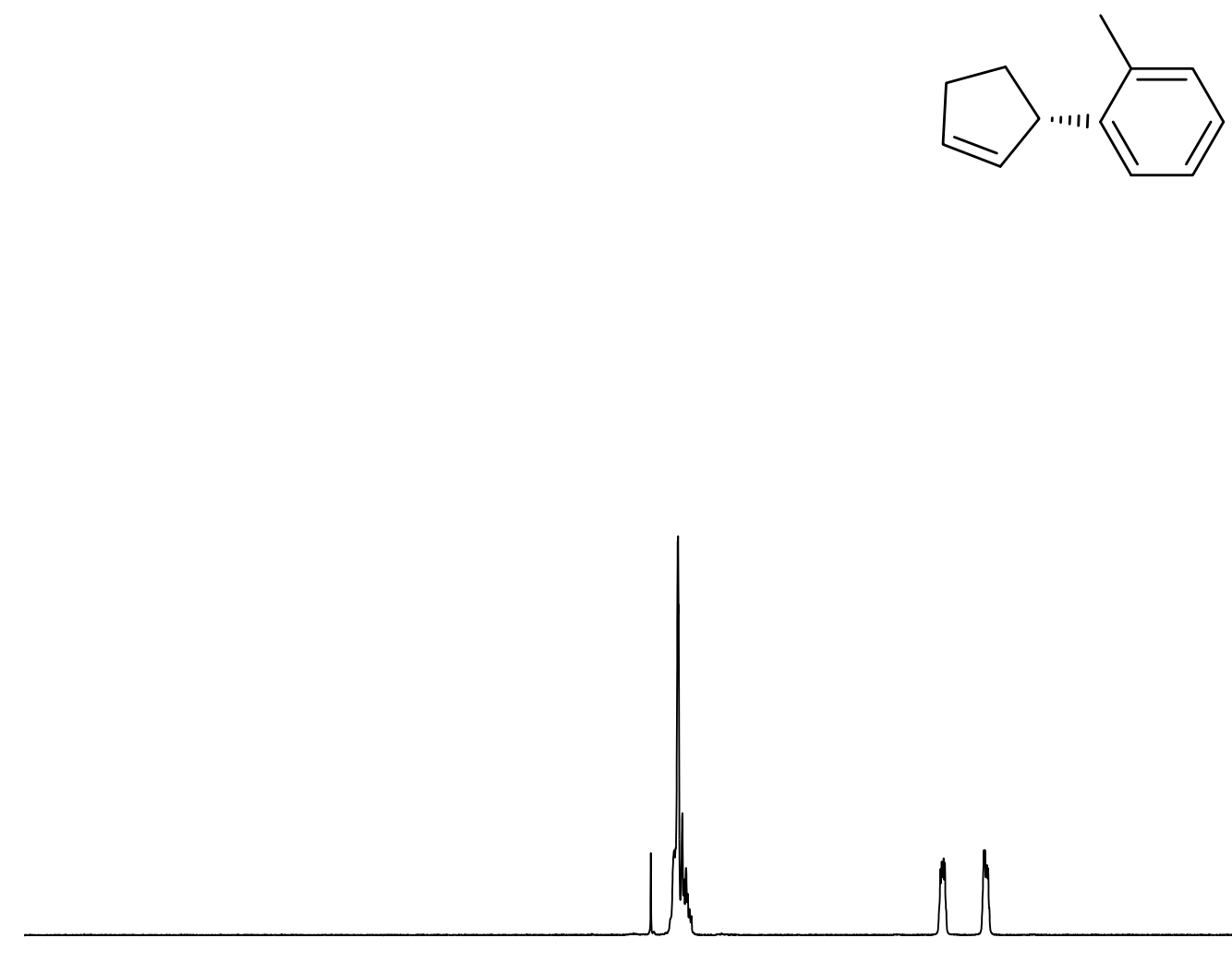

5

4

3

$\left|\begin{array}{l}\infty \\ 0 \\ 0 \\ m\end{array}\right|$

2 $\left|\begin{array}{l}0 \\ 0 \\ r\end{array}\right|$ 
WCL4039-D-1H, BBF01 26-09-2013

舟 윰

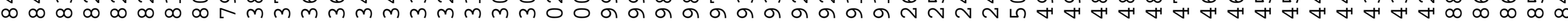

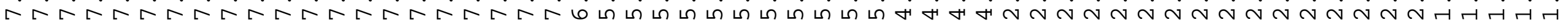
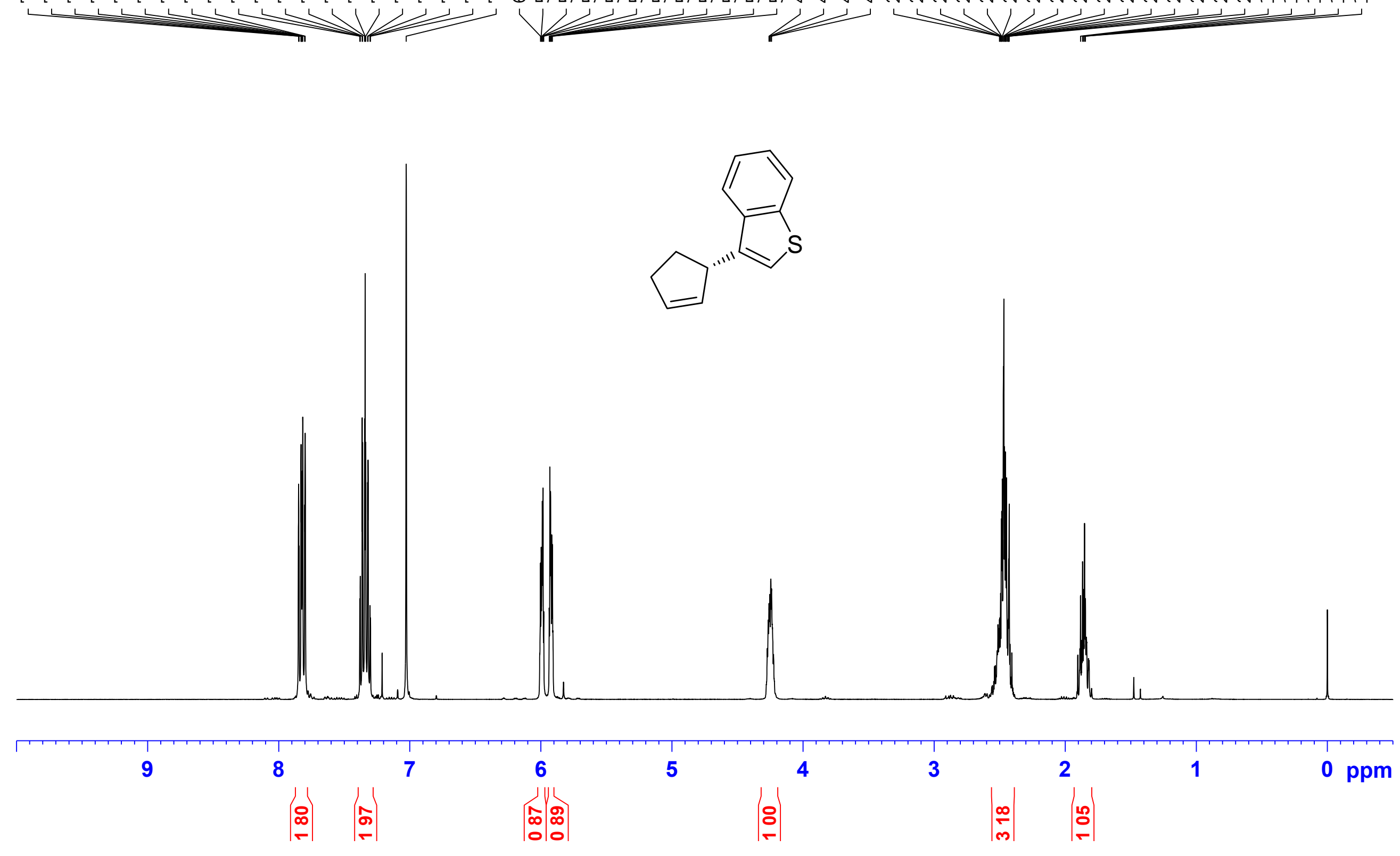
WCL4039-D13C， BBF01 26-09-2013

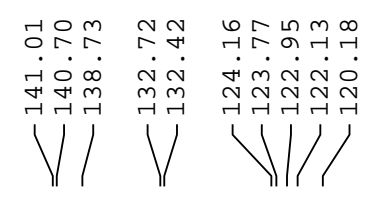

$$
\begin{aligned}
& \text { 스ㄹㅠㅠ } \\
& \text { กิ่อ }
\end{aligned}
$$
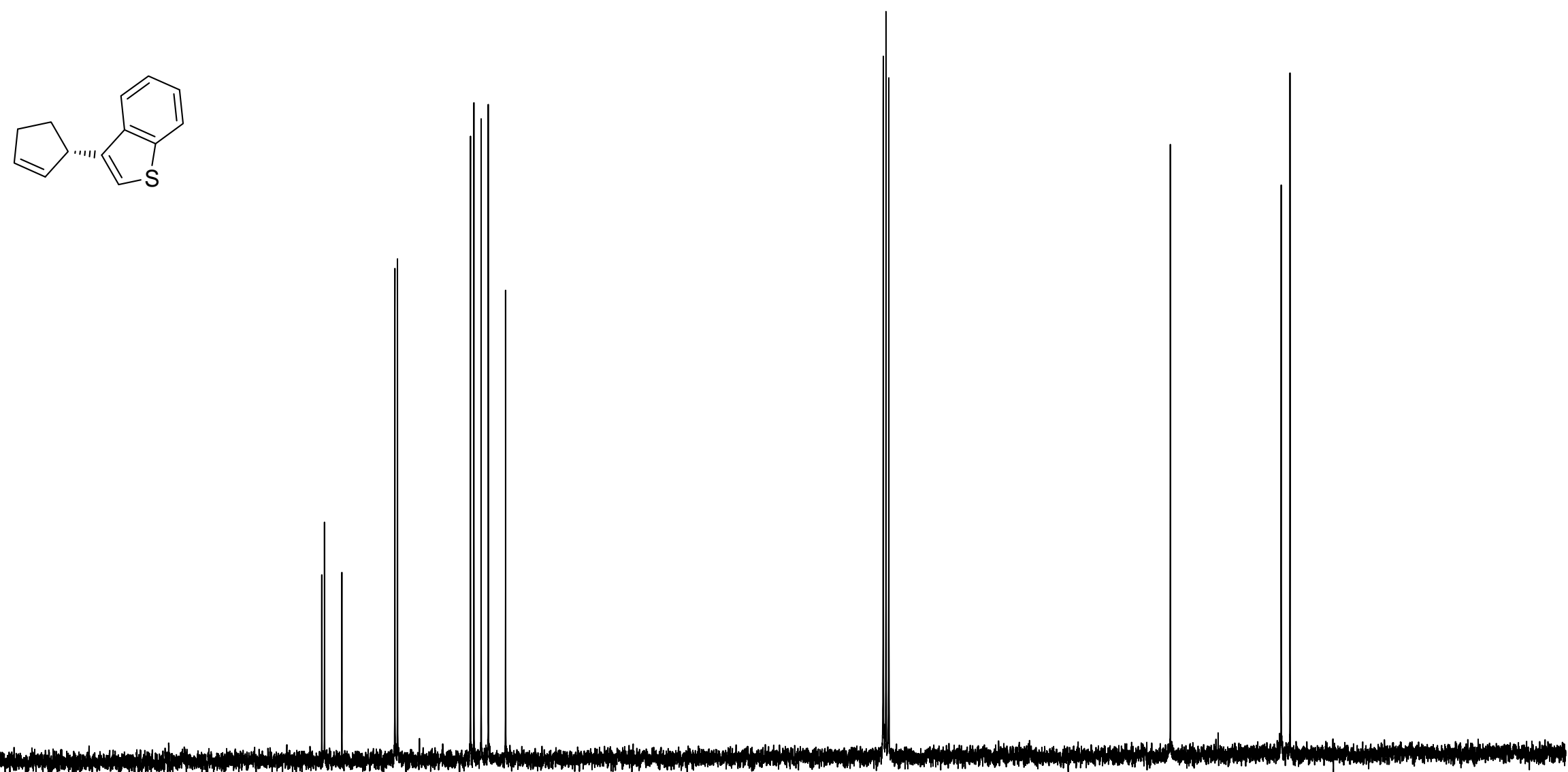

50

040


WCL4044-B-1H-2, BBF01, 23-0ct-2013

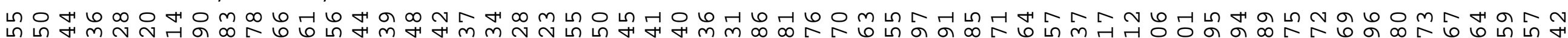

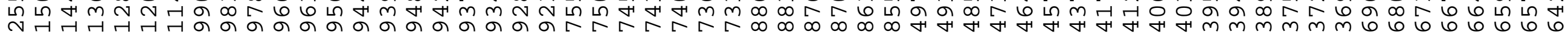
NANA
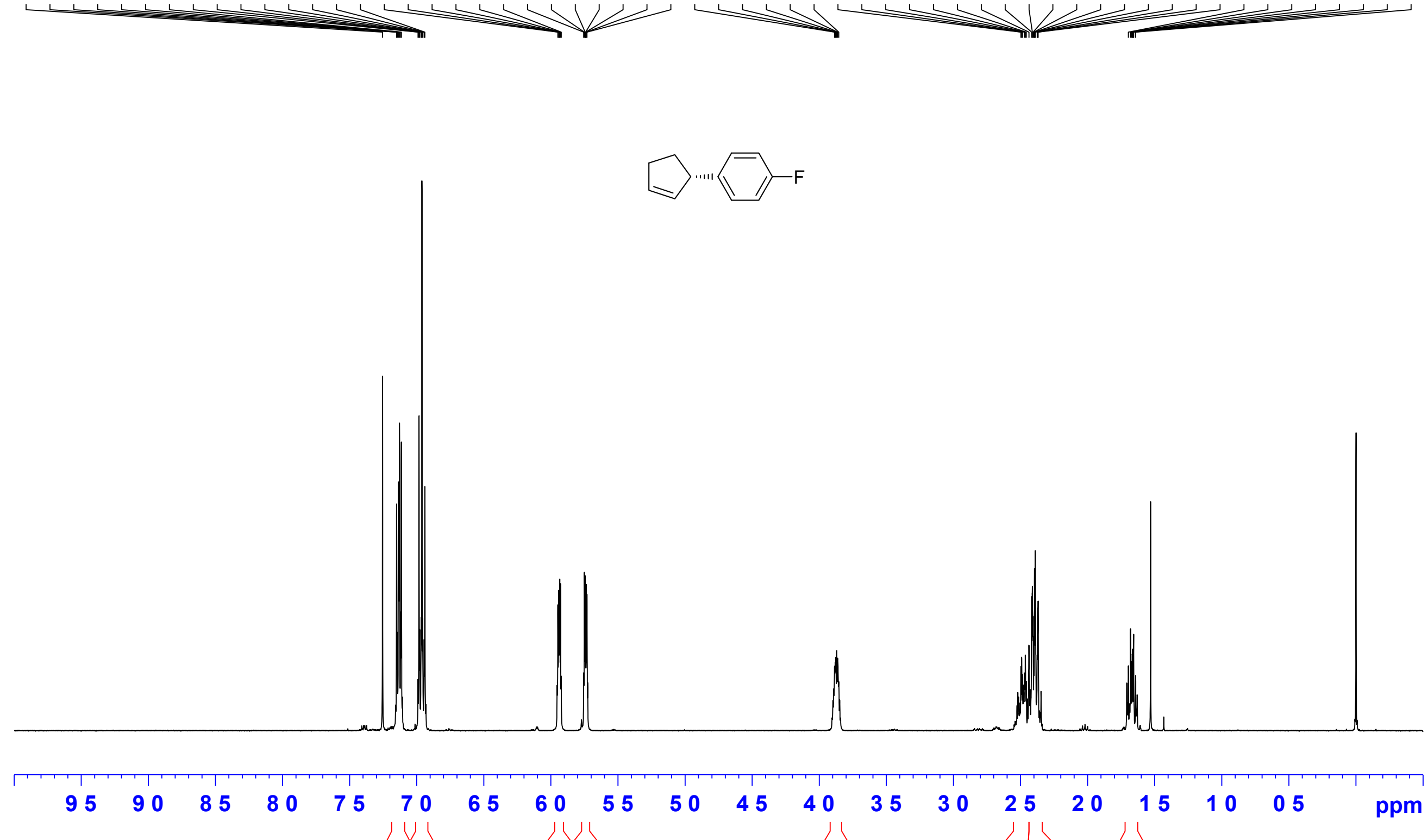

$\left|\begin{array}{l|l}7 & 0 \\ & 0 \\ \text { N } & 0 \\ N\end{array}\right|$
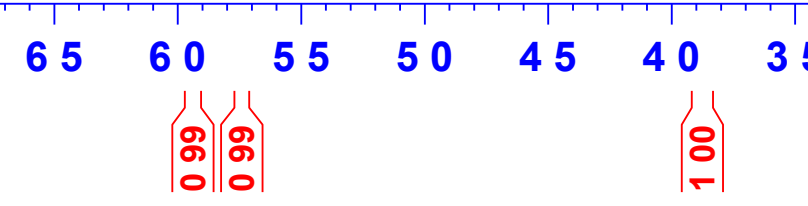

353 
WCL4065-D-1H, av500, 22-0ct-2013

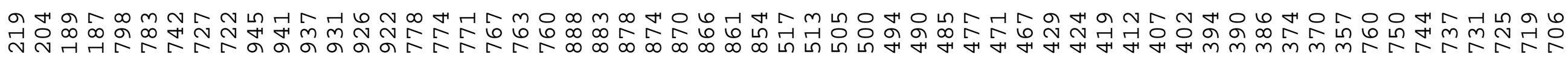
R

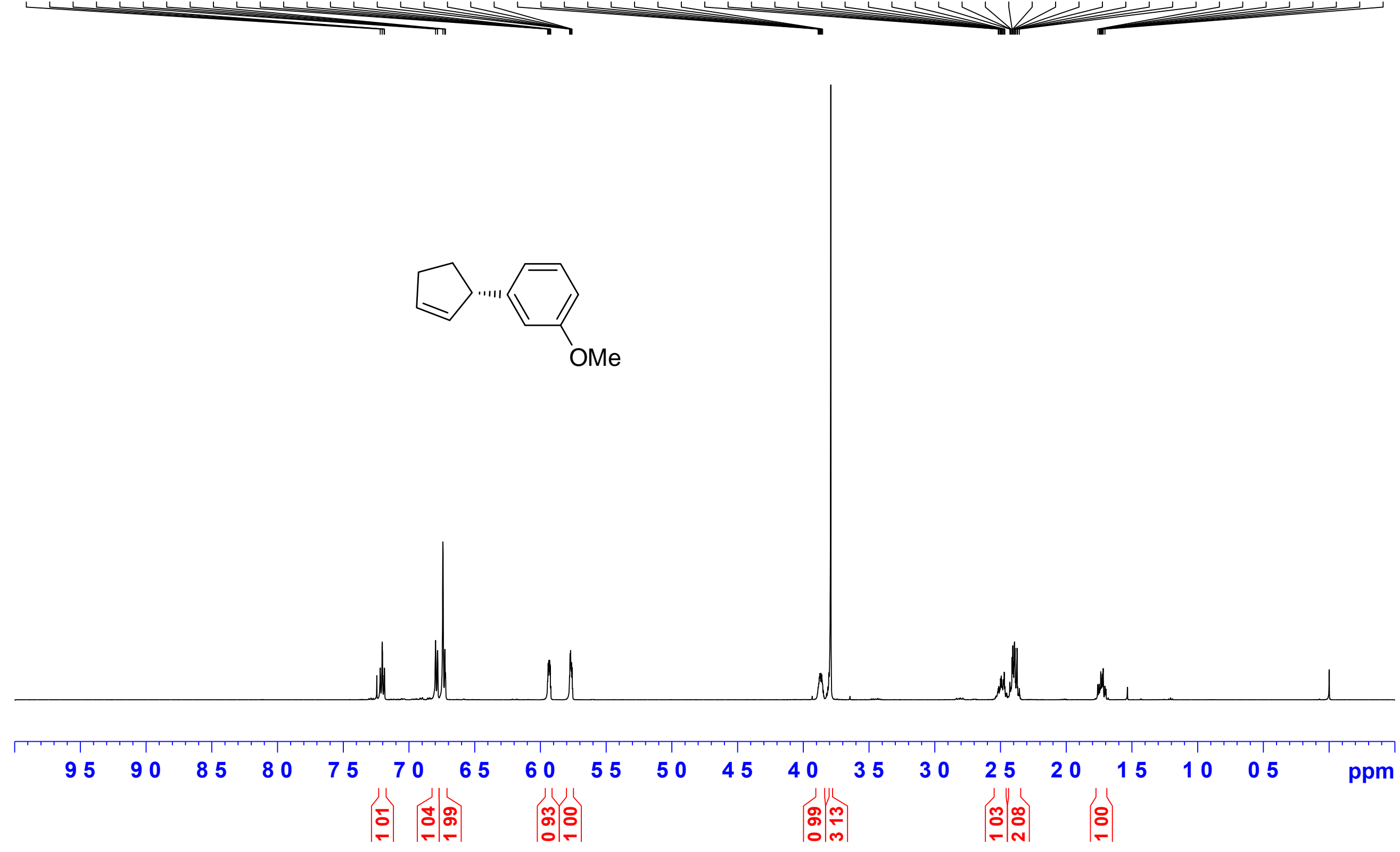


WCL4029-B 1HNMR BBF01 CDCl3 2013-8-22

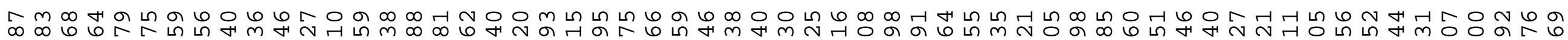
N ש

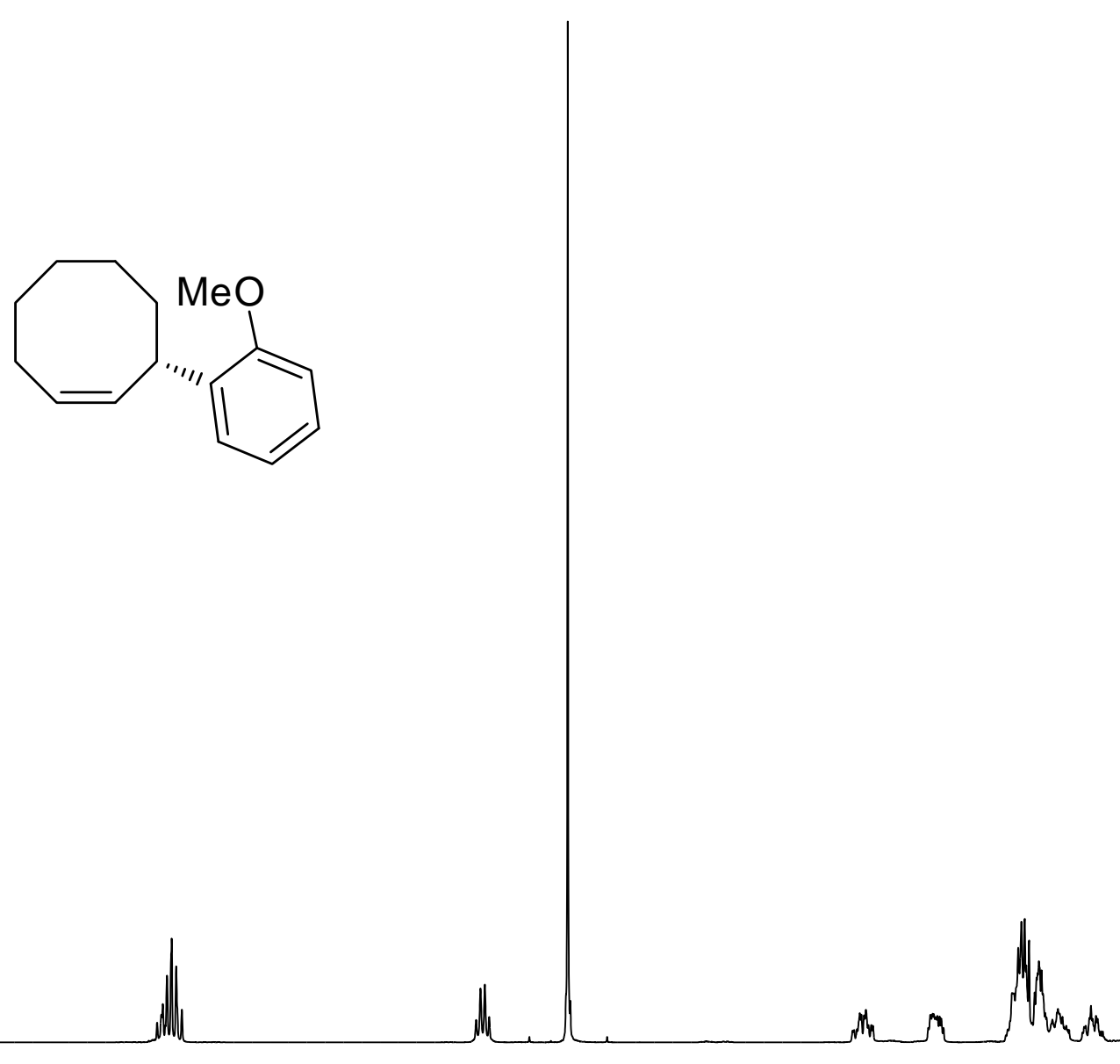

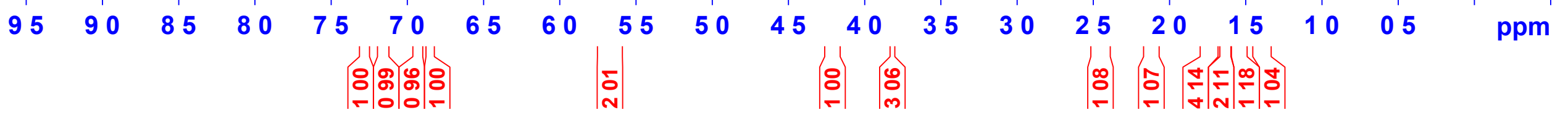


WCL4029-B 13CNMR BBF01 CDCl3 2013-8-22

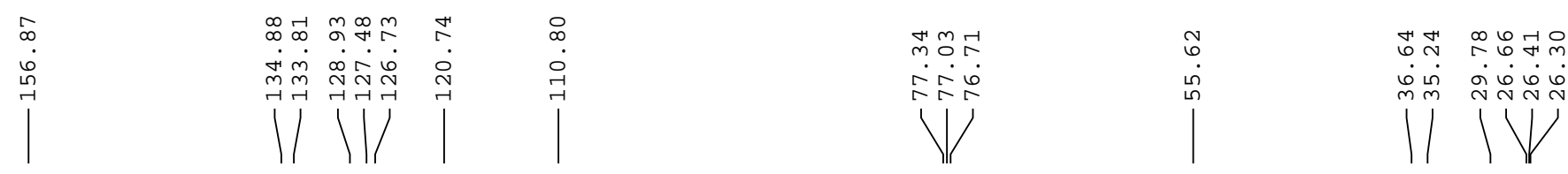

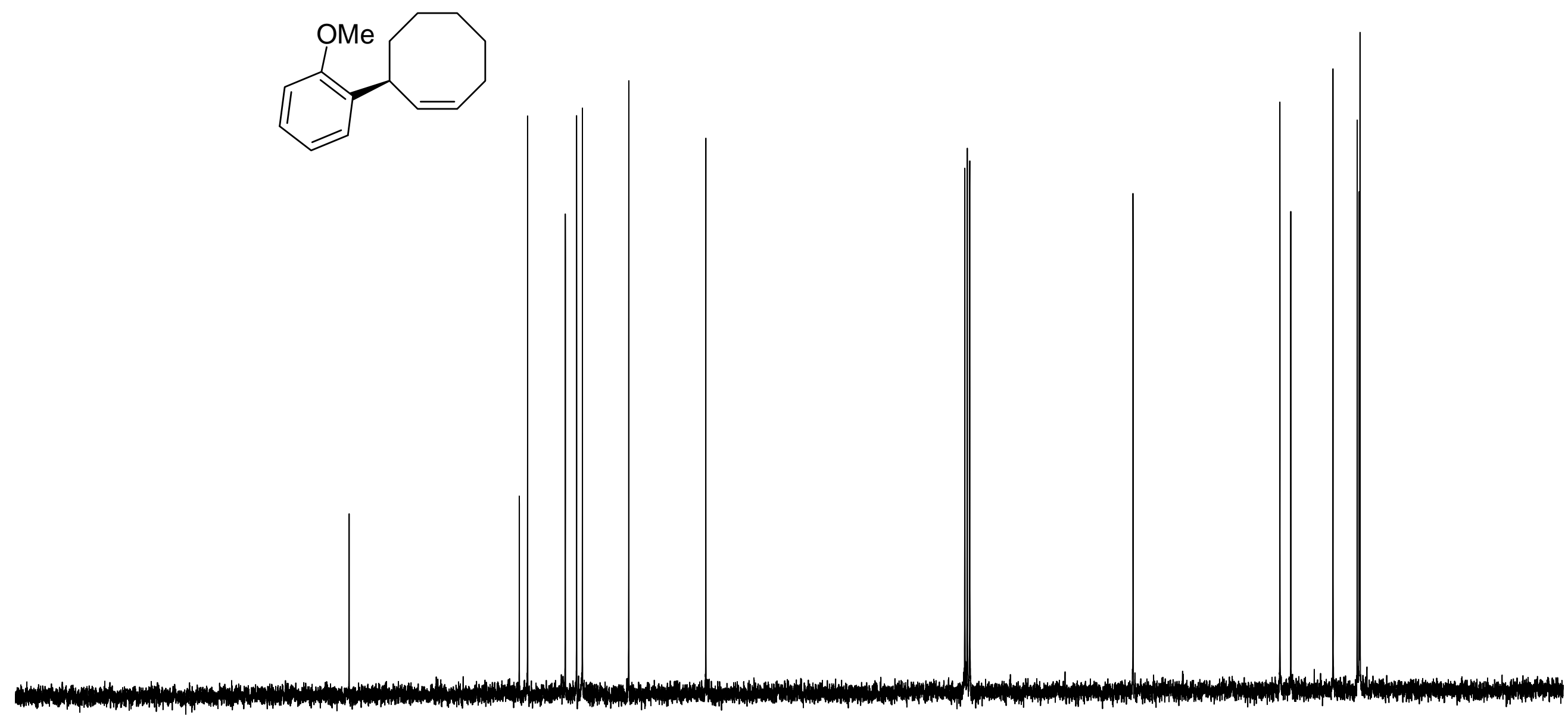

\begin{tabular}{|c|c|c|c|c|c|c|c|c|c|c|c|c|c|c|c|c|}
\hline 190 & 180 & 170 & 160 & 150 & 140 & 130 & 120 & 110 & 100 & 90 & 80 & 70 & 60 & 50 & 40 & ppm \\
\hline
\end{tabular}


WCL4029-A 13CNMR BBF01 CDCl3 2013-8-22

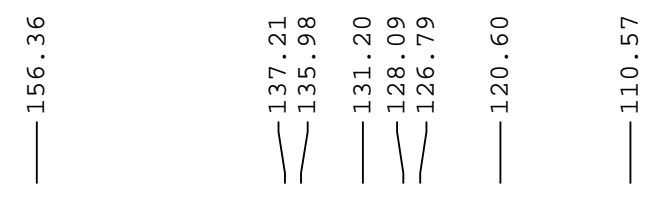

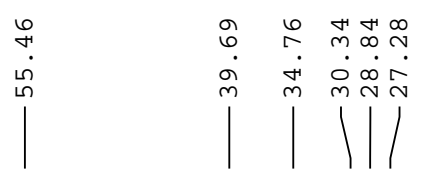<smiles>COc1ccccc1[C@H]1C=CCCCC1</smiles>

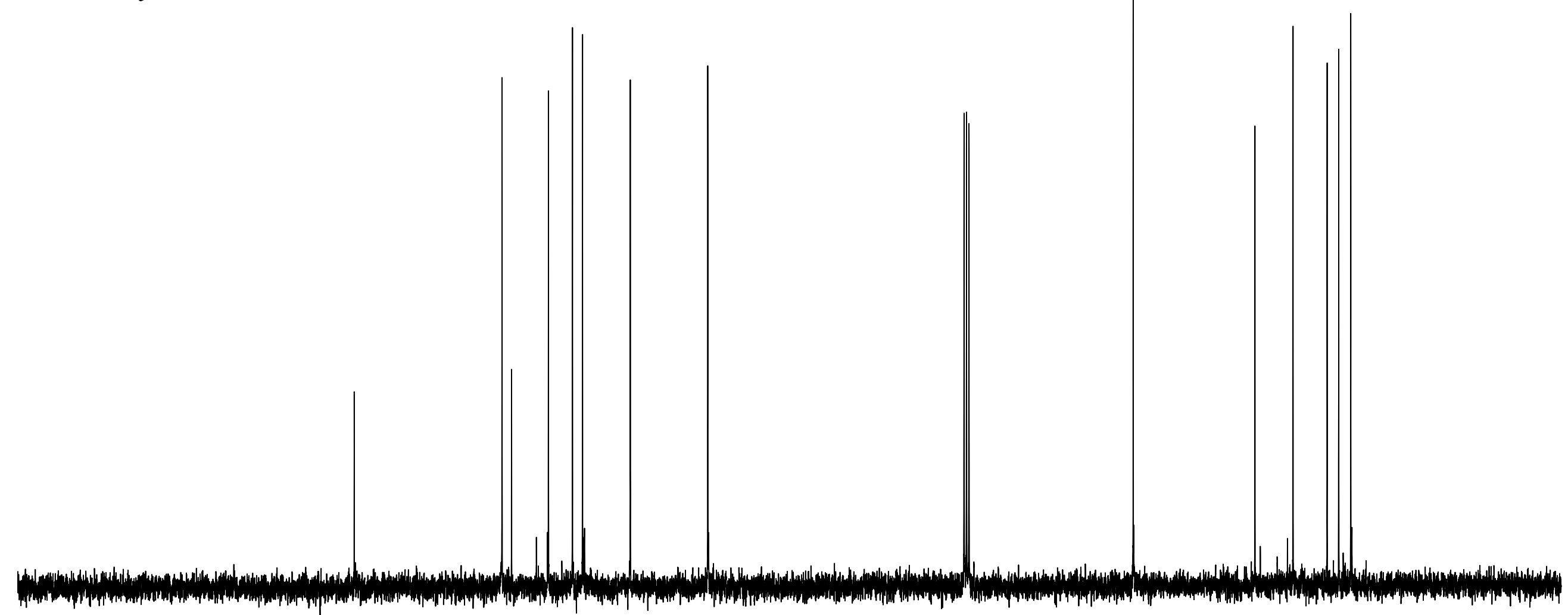


WCL4029-A1HNMR BBF01 CDCl3 2013-8-22

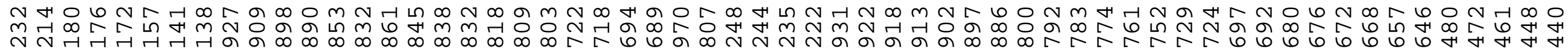

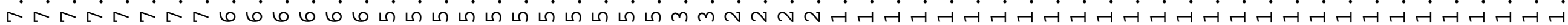
Tा11 $1 \mathrm{~m}$
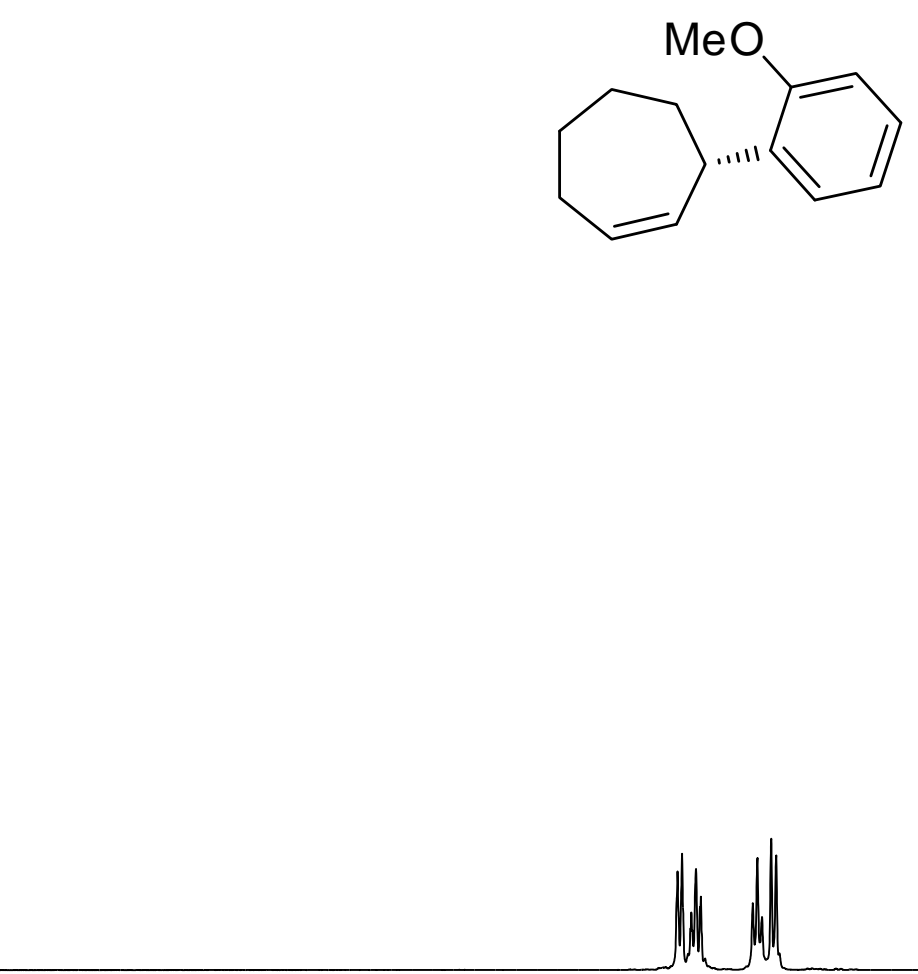
Nh

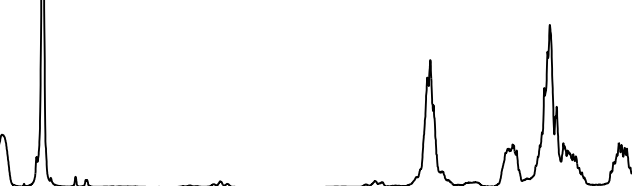

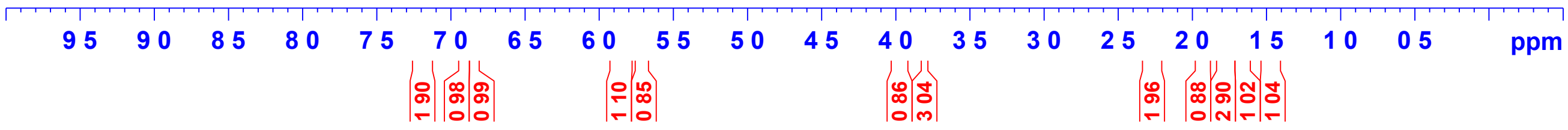




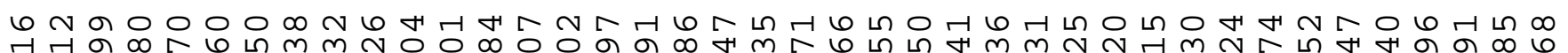
m

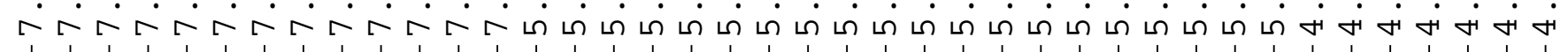
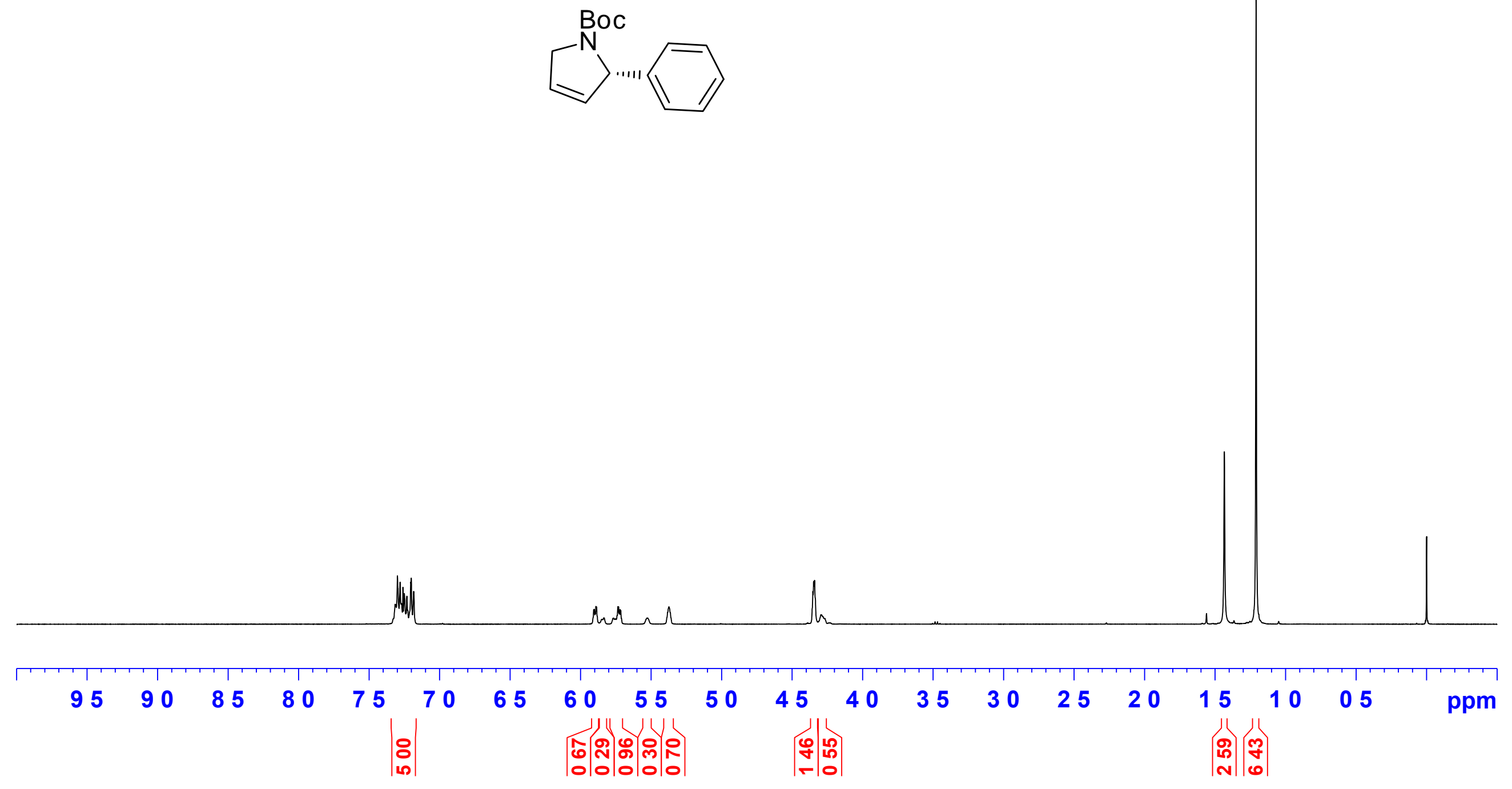
WCL4017-B-1H, BBF01 07-09-2013

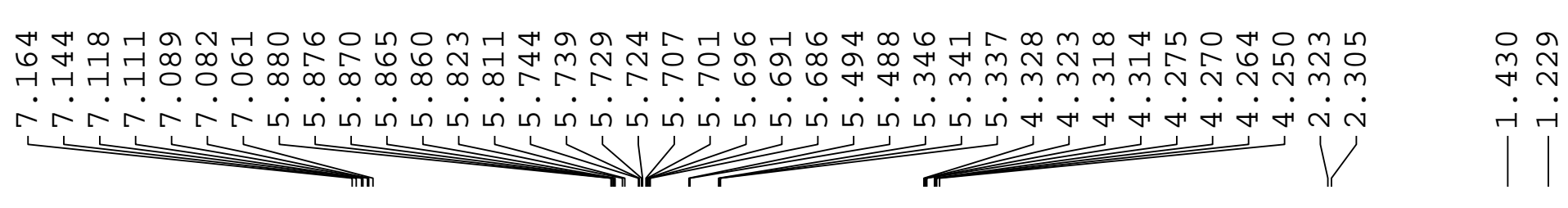

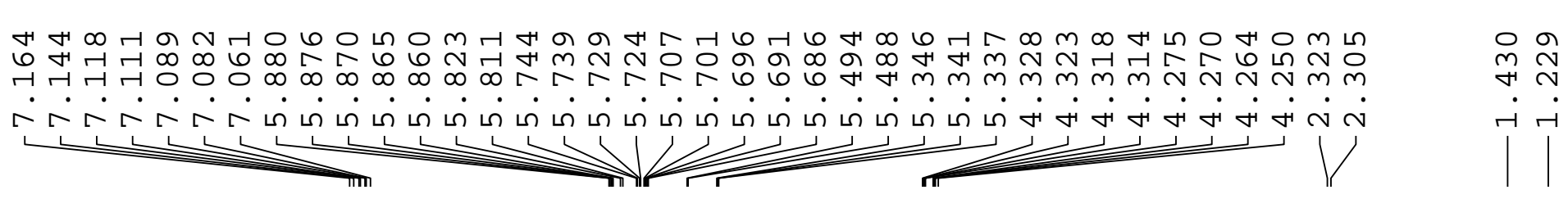
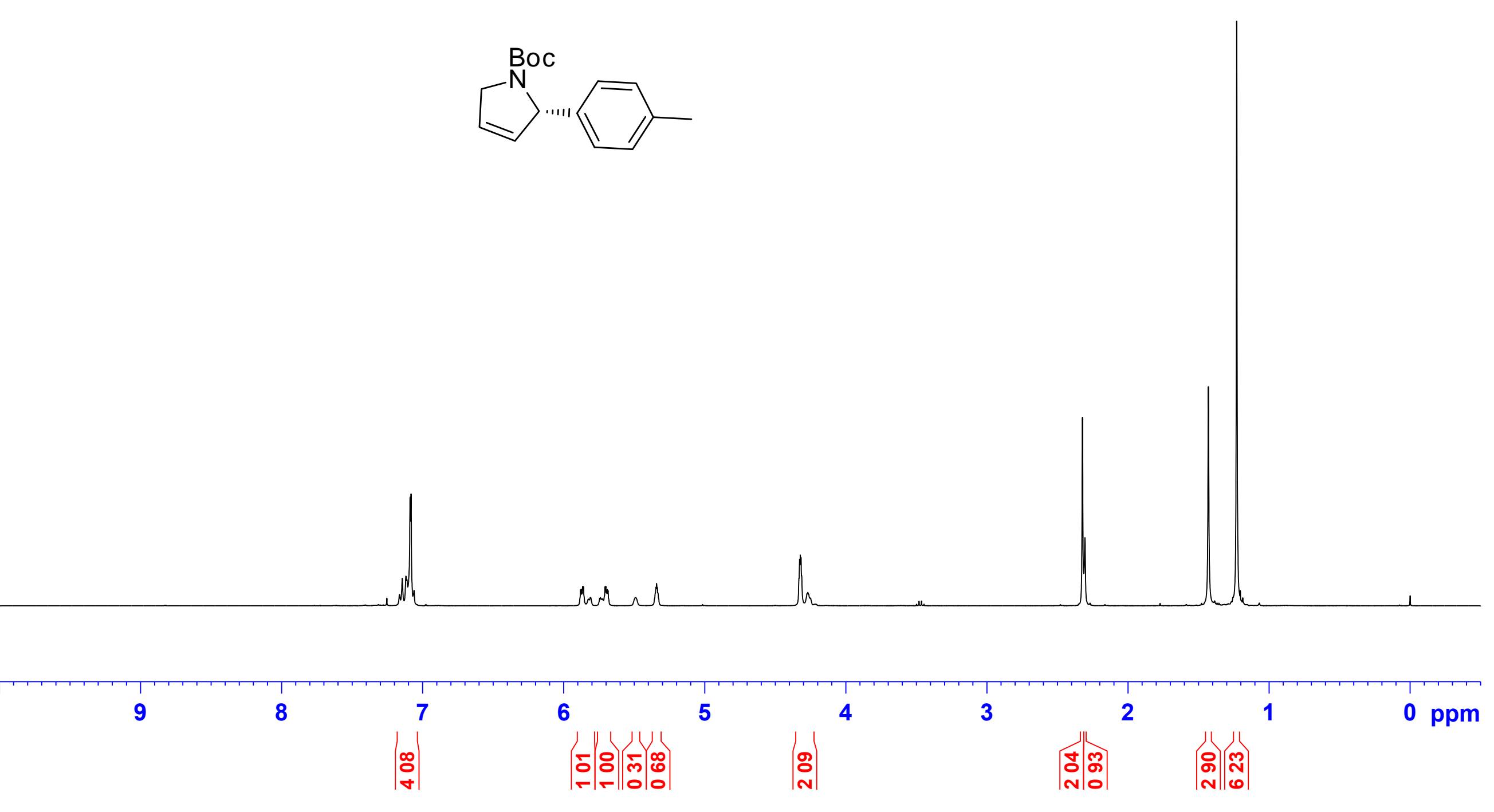

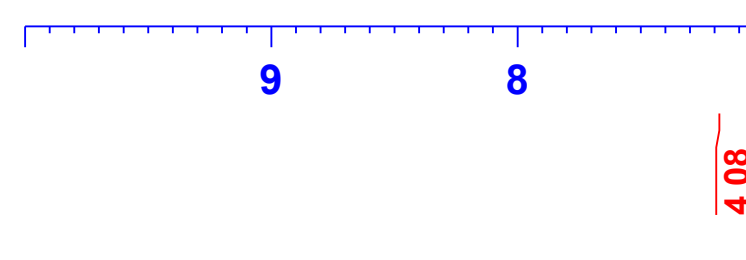

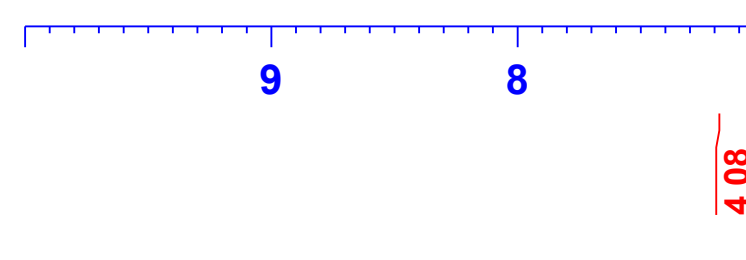

\begin{tabular}{|c|c|}
\hline 7 & 6 \\
\hline$\left|\begin{array}{l}\infty \\
0 \\
8\end{array}\right|$ & 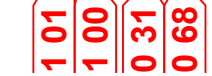 \\
\hline
\end{tabular}
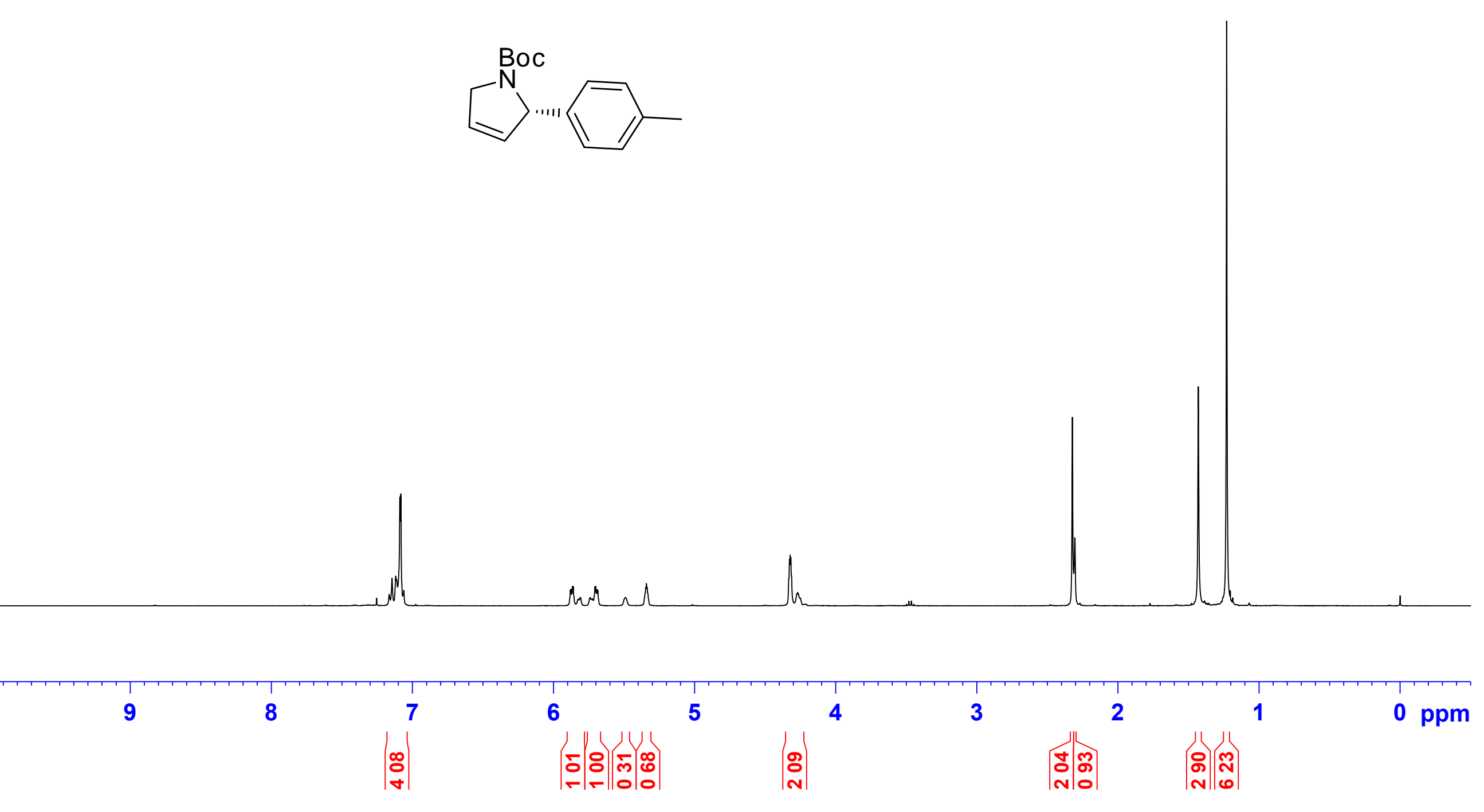

0 ppm

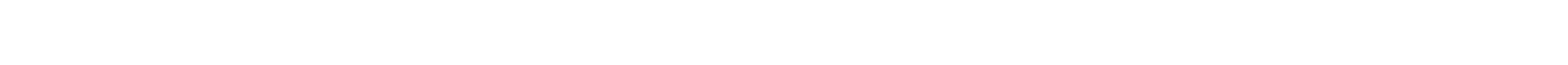
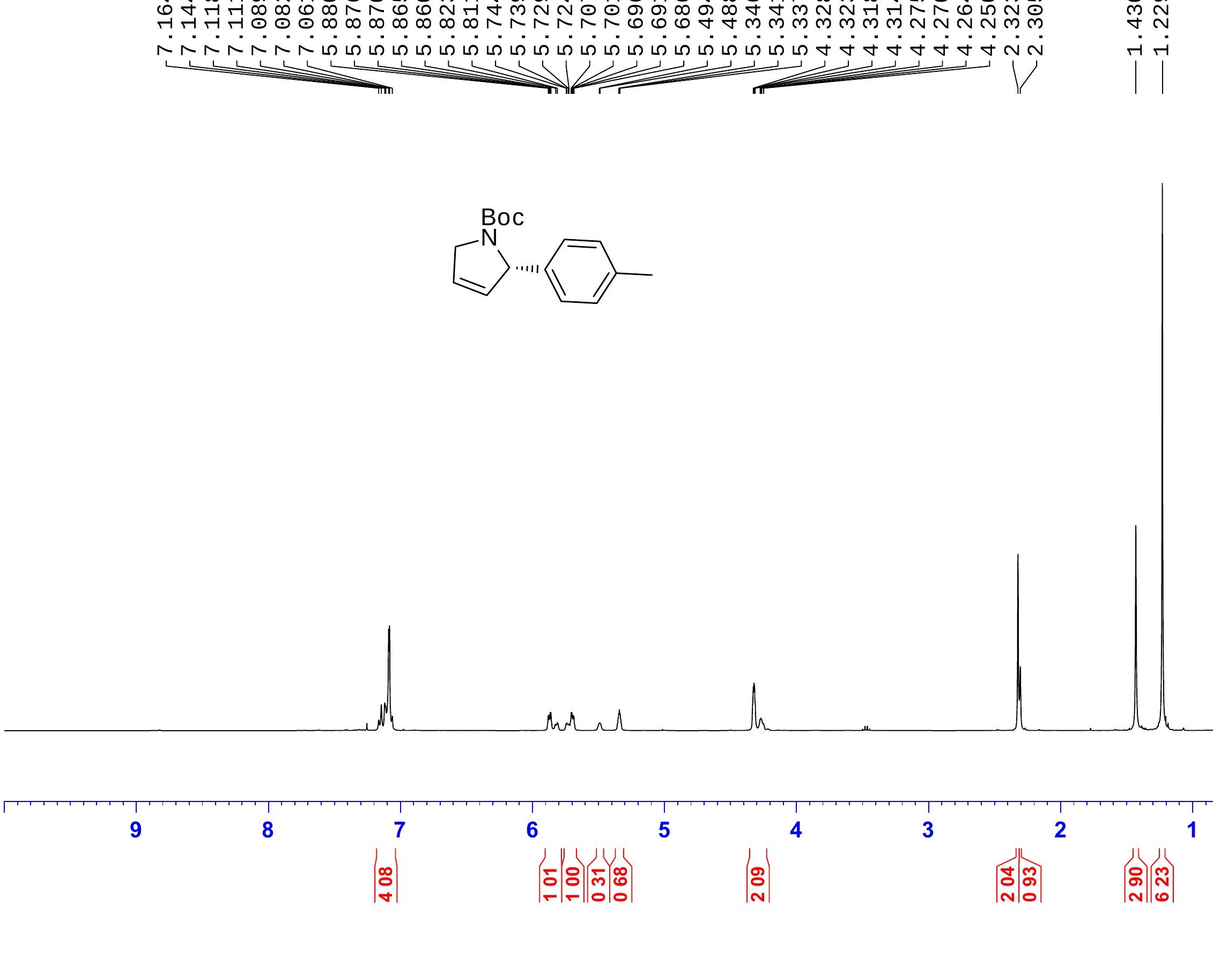

(n)


WCL4017-B-13C， BBF01 07- ๑9-2013
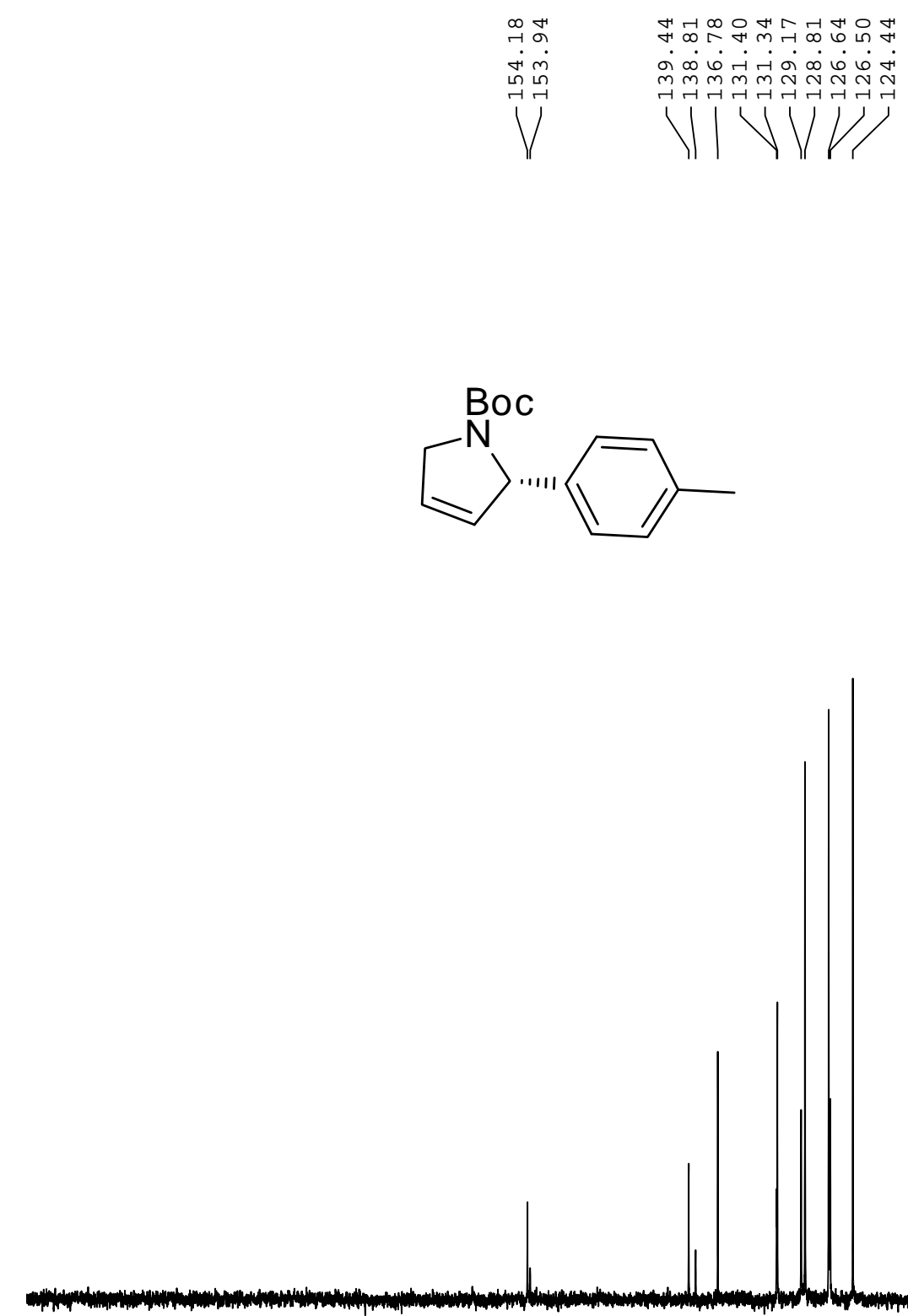


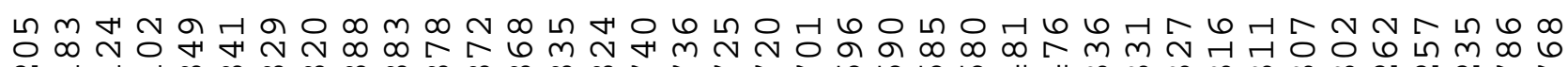
N H 的
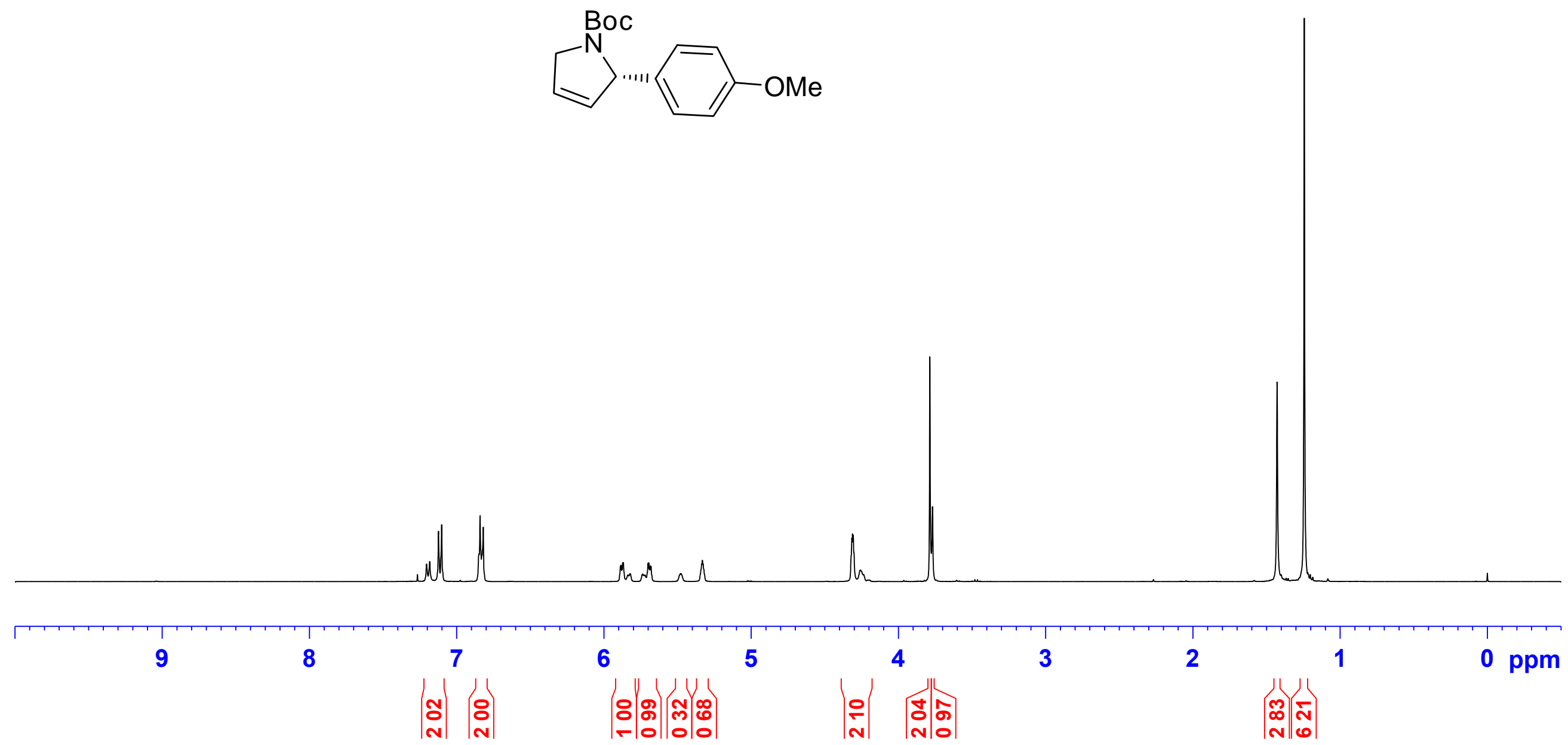
WCL4017-E-13C， BBF01 07-09-2013
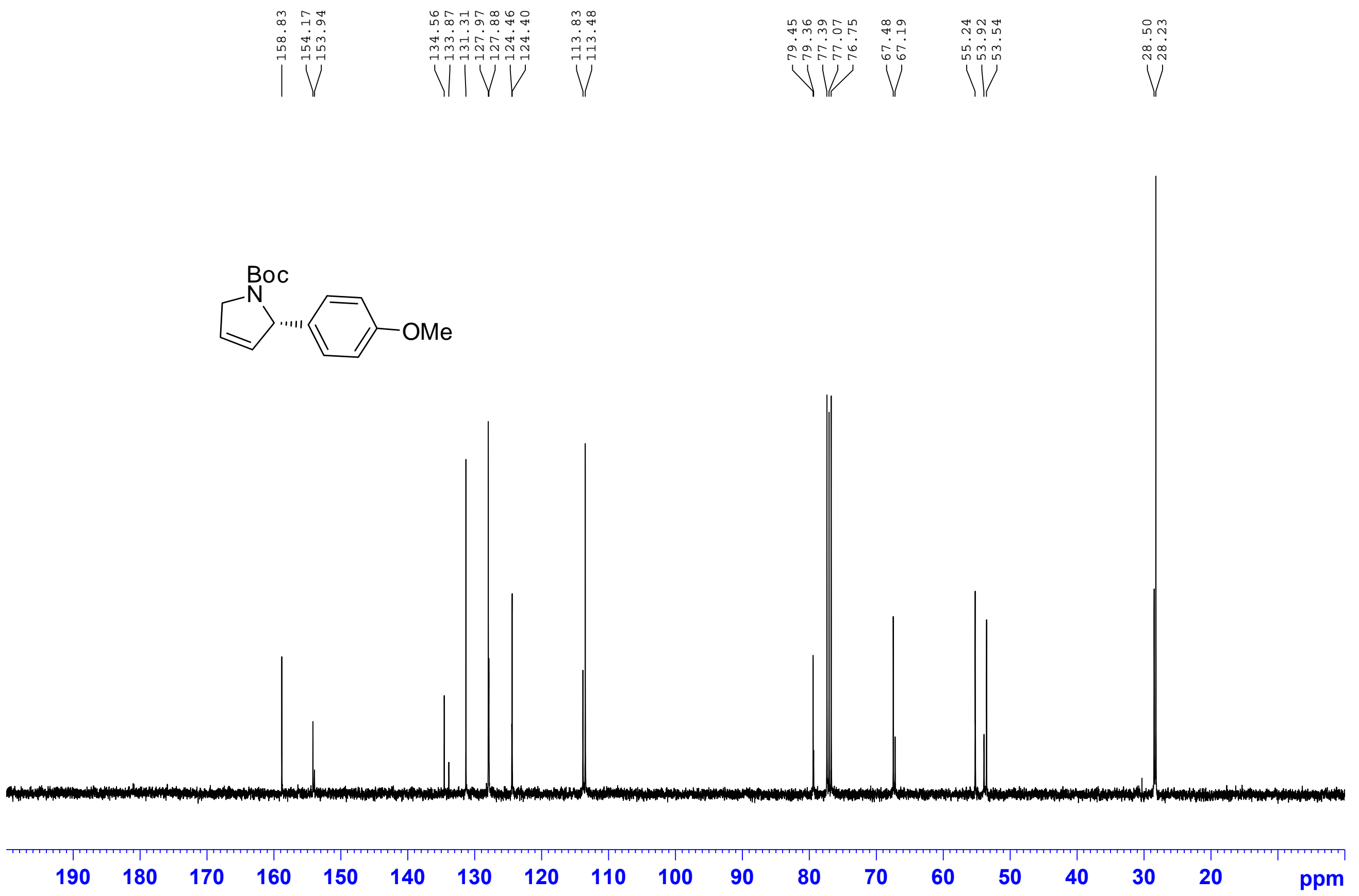
WCL4017-F-1H, av500, 22-0ct-2013

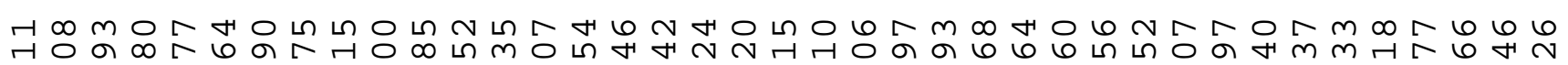

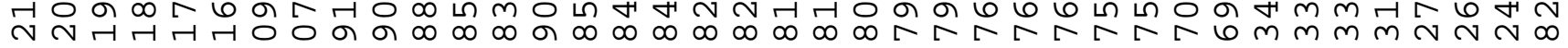
ヘ 2.

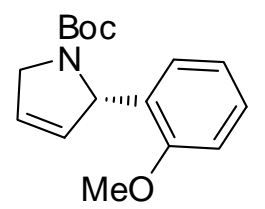
Nh

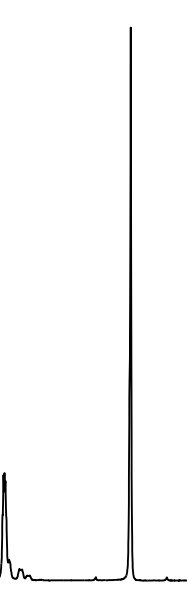


wc14061B-13C,1H, CDCl3 BBF01 400MHz, 2013, 01, Nov
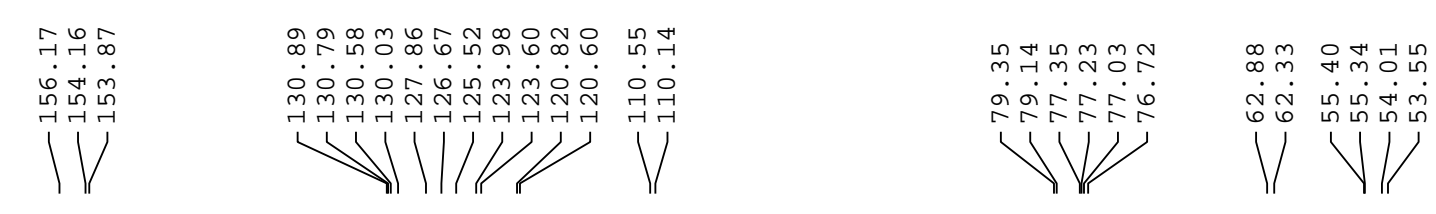

용유

$\stackrel{\infty}{\infty}$

นค่ำ

V V

N<smiles>COc1ccccc1[C@H]1C=CCN1C(=O)OC(C)(C)C</smiles>

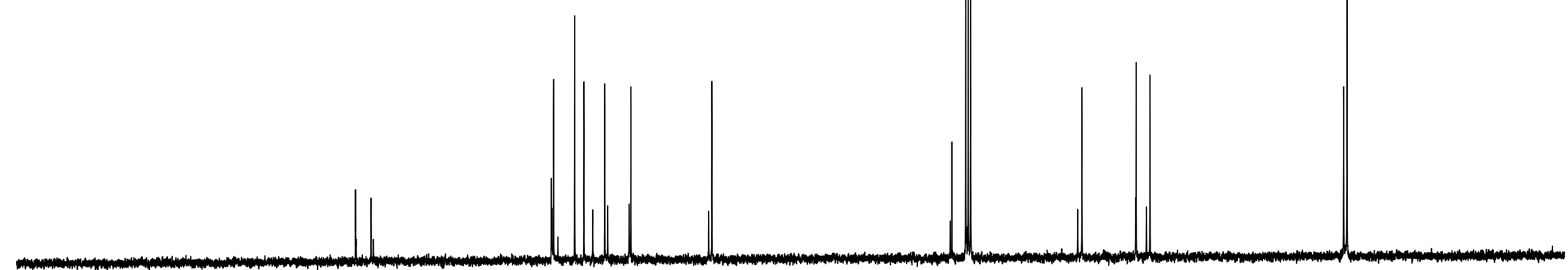

5040


WCL4021-D-1H, av500, 22-0ct-2013

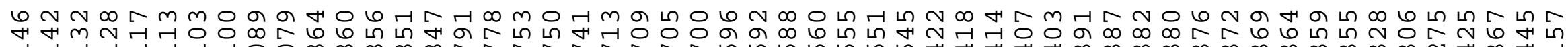
卉年

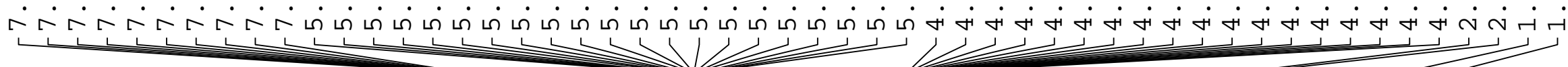
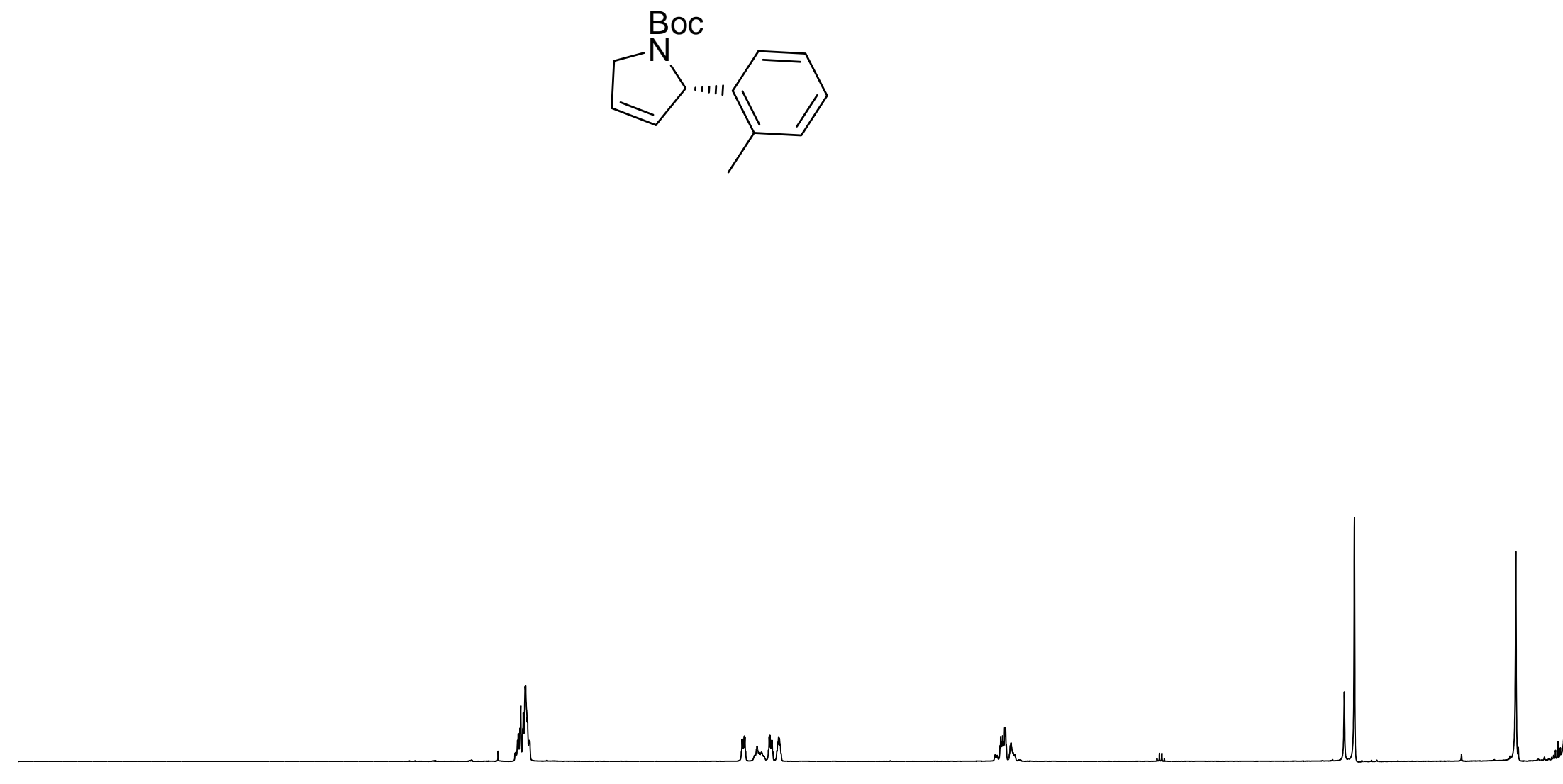

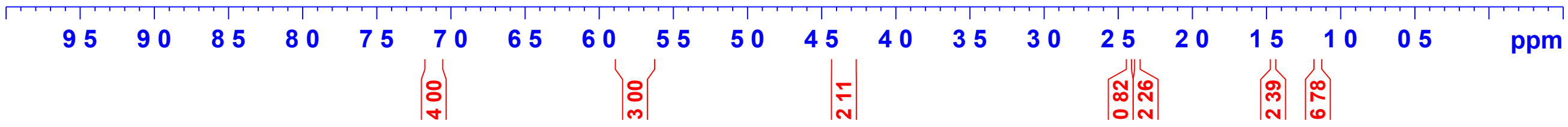


WCL4021-D-13C, av500, 22-0ct-2013

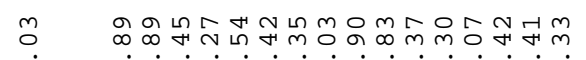

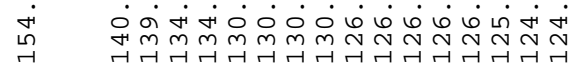

1
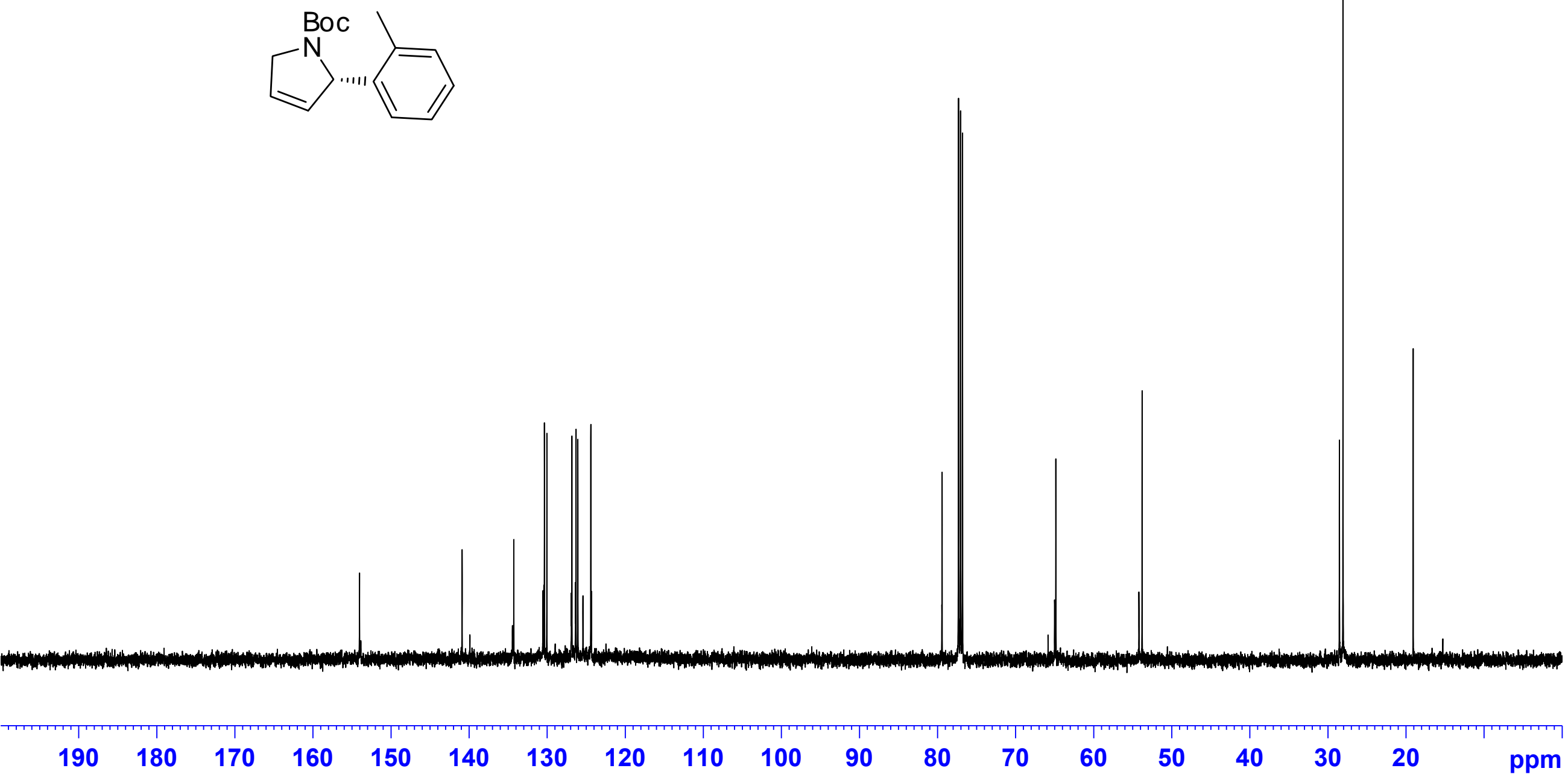
WCL4052-E-1H， BBF01 24-09-2013

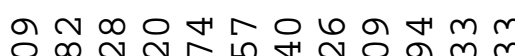

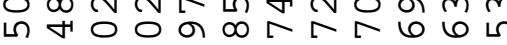

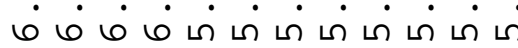
$>1$ $\unrhd \infty \sim \infty \infty$

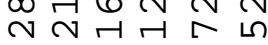

षंषंषं ले

$1 /$ $m$

4i

1

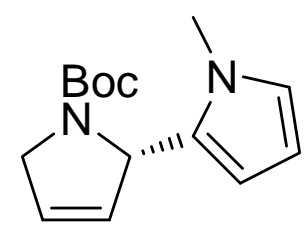

Ithe
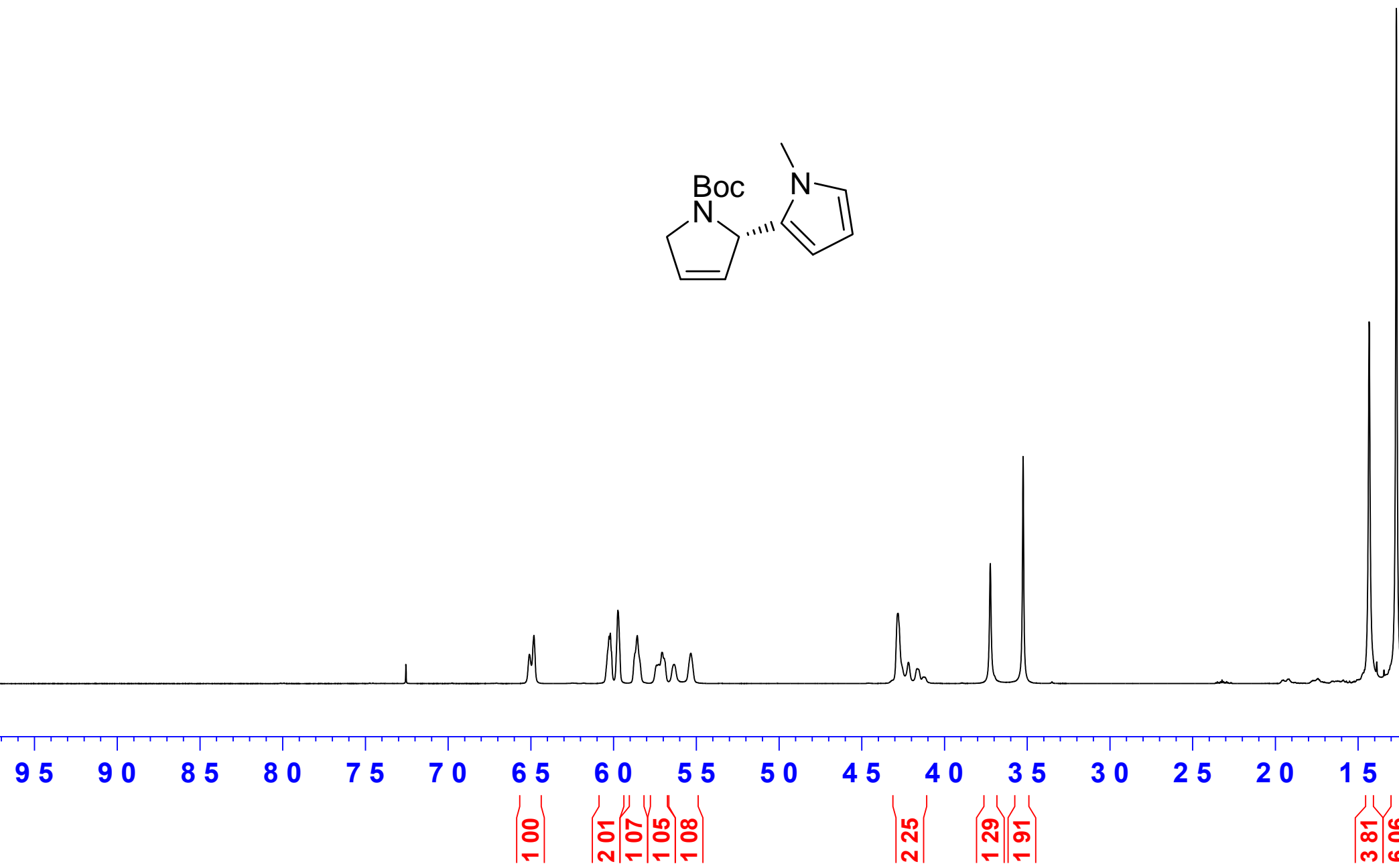

35
5
5

25

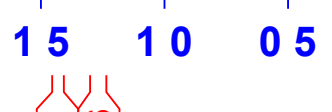

$\left(\begin{array}{lll}5 & 0 \\ \infty & 0 \\ m & 0\end{array}\right)$ 
WCL4052-E-13C, av500, 22-0ct-2013

V)
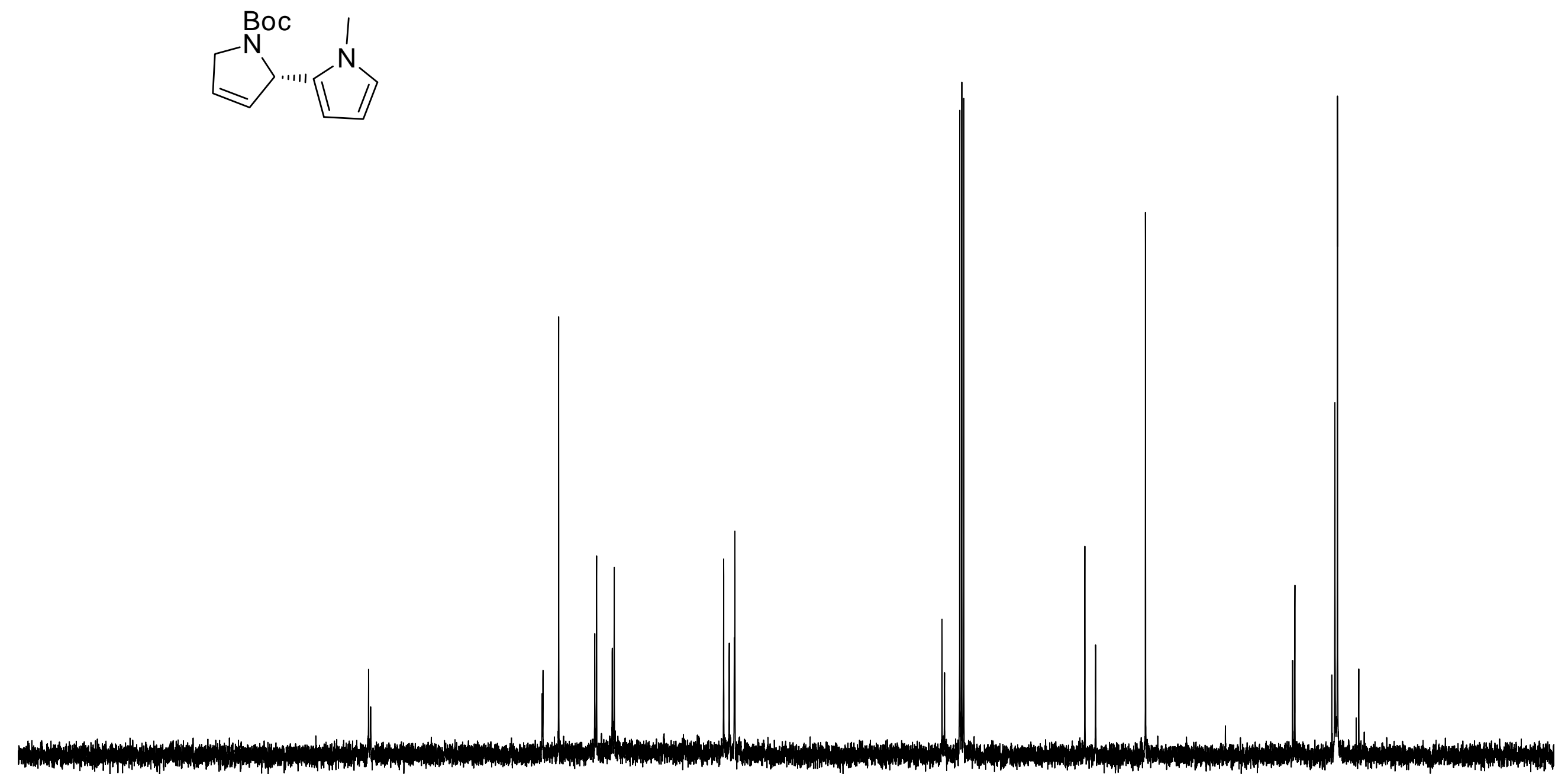
WCL4063-B-1H, BBF01, 23-0ct-2013

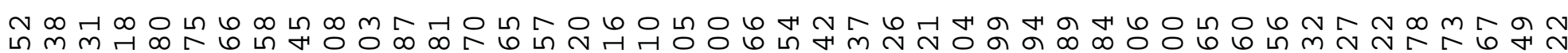
뉴N ה
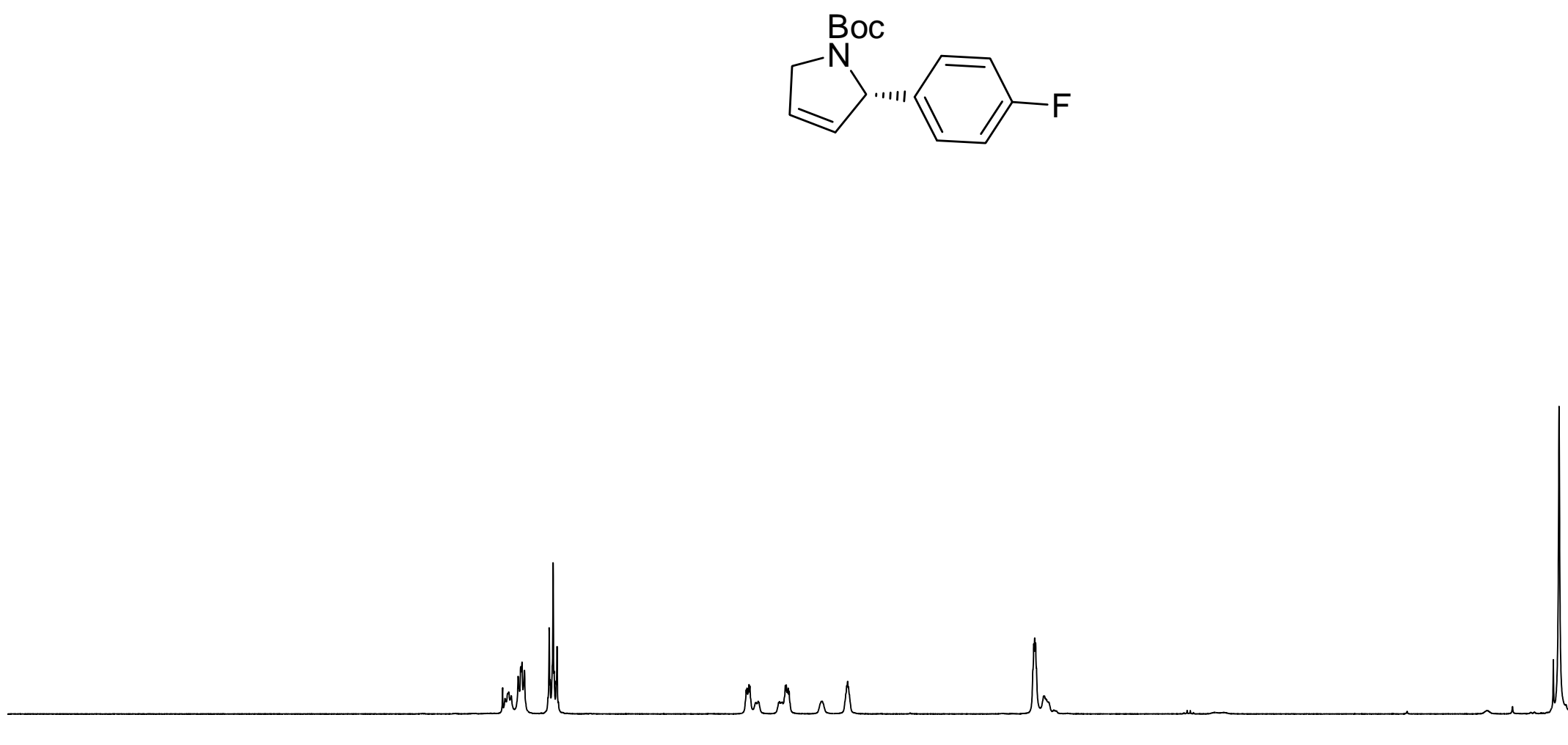

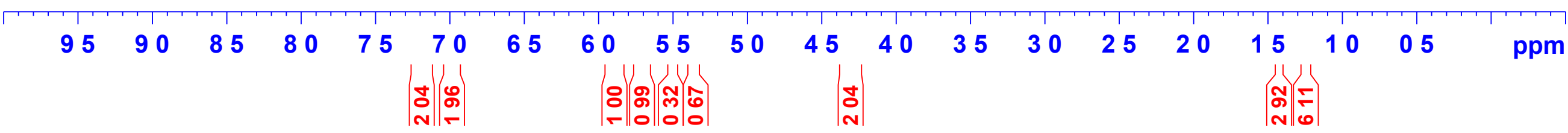


WCL4063-B-13C， BBF01，23-0ct-2013
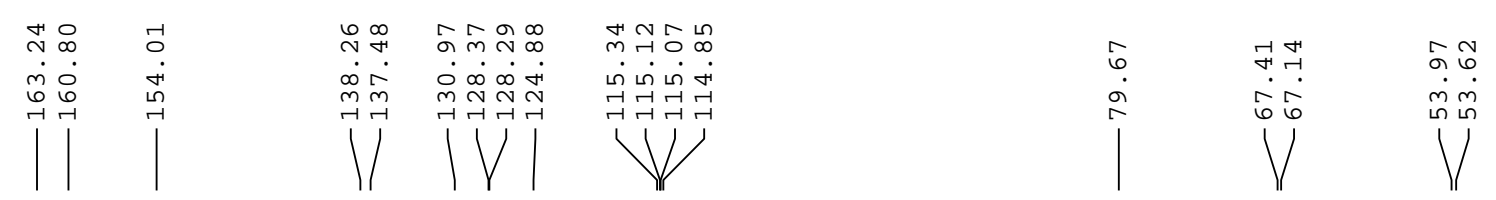

ㄷำ

||$^{\infty}$

$\min ^{\infty}$

$\stackrel{\infty}{\sim} \stackrel{\infty}{N}$

\section{.}

Boc
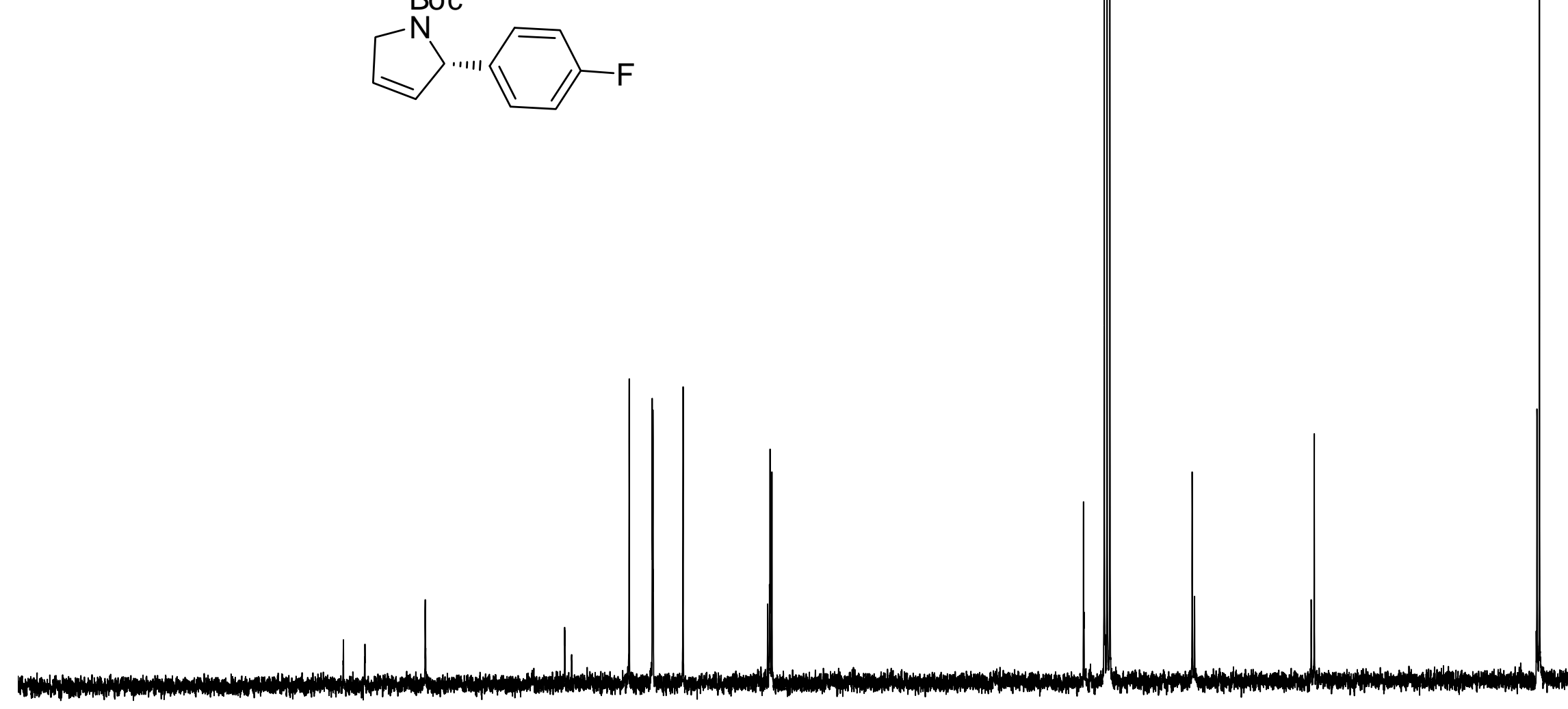
WCL4063-B-19F, BBFO1, 30-OCt-2013

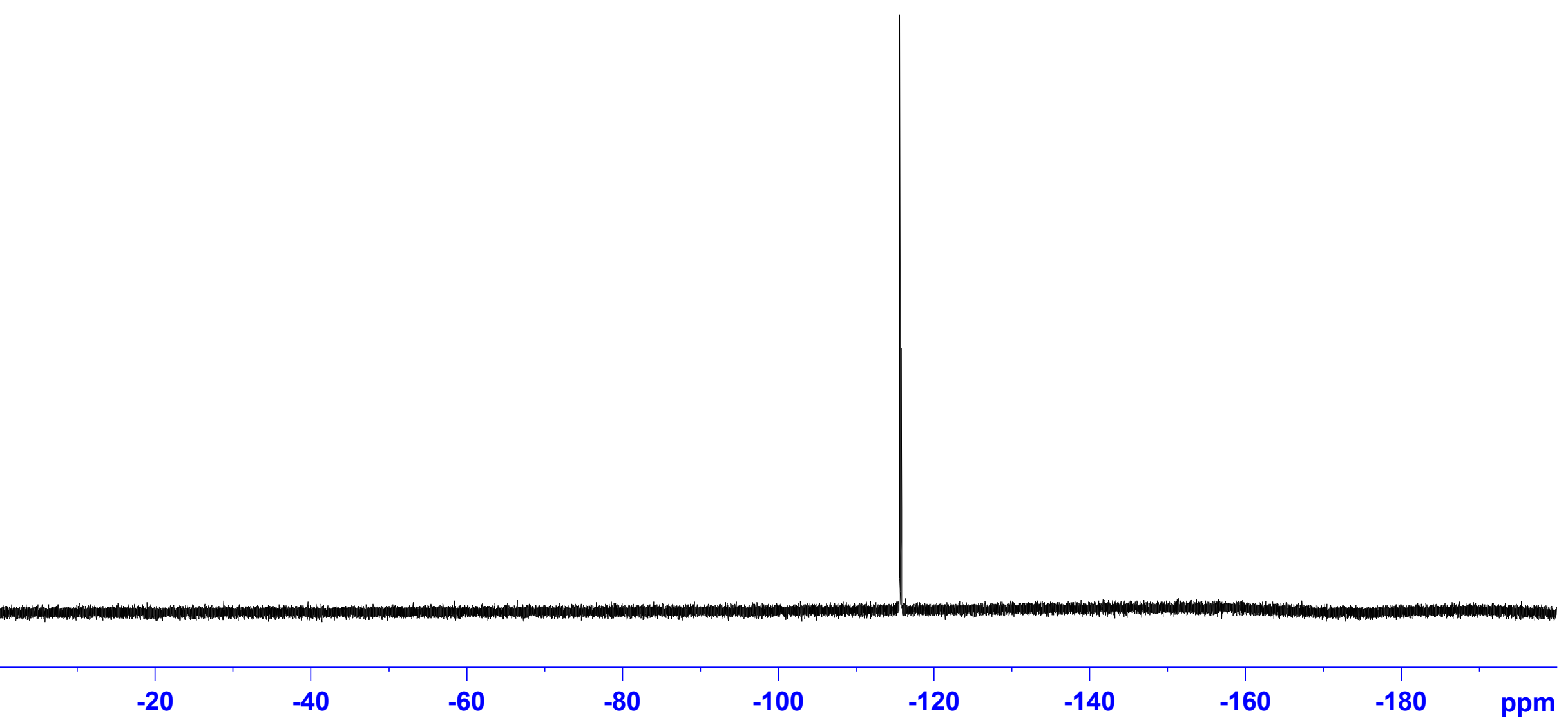


Complex-75 upscale 1H 1H AV500 13 Nov 2013

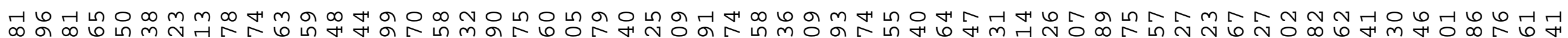

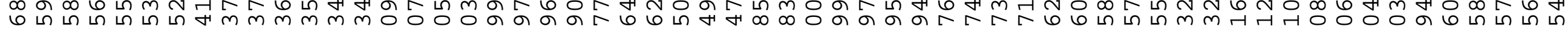

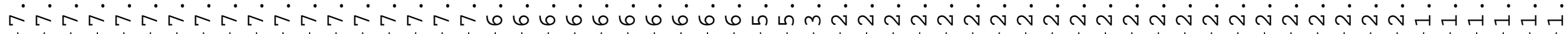
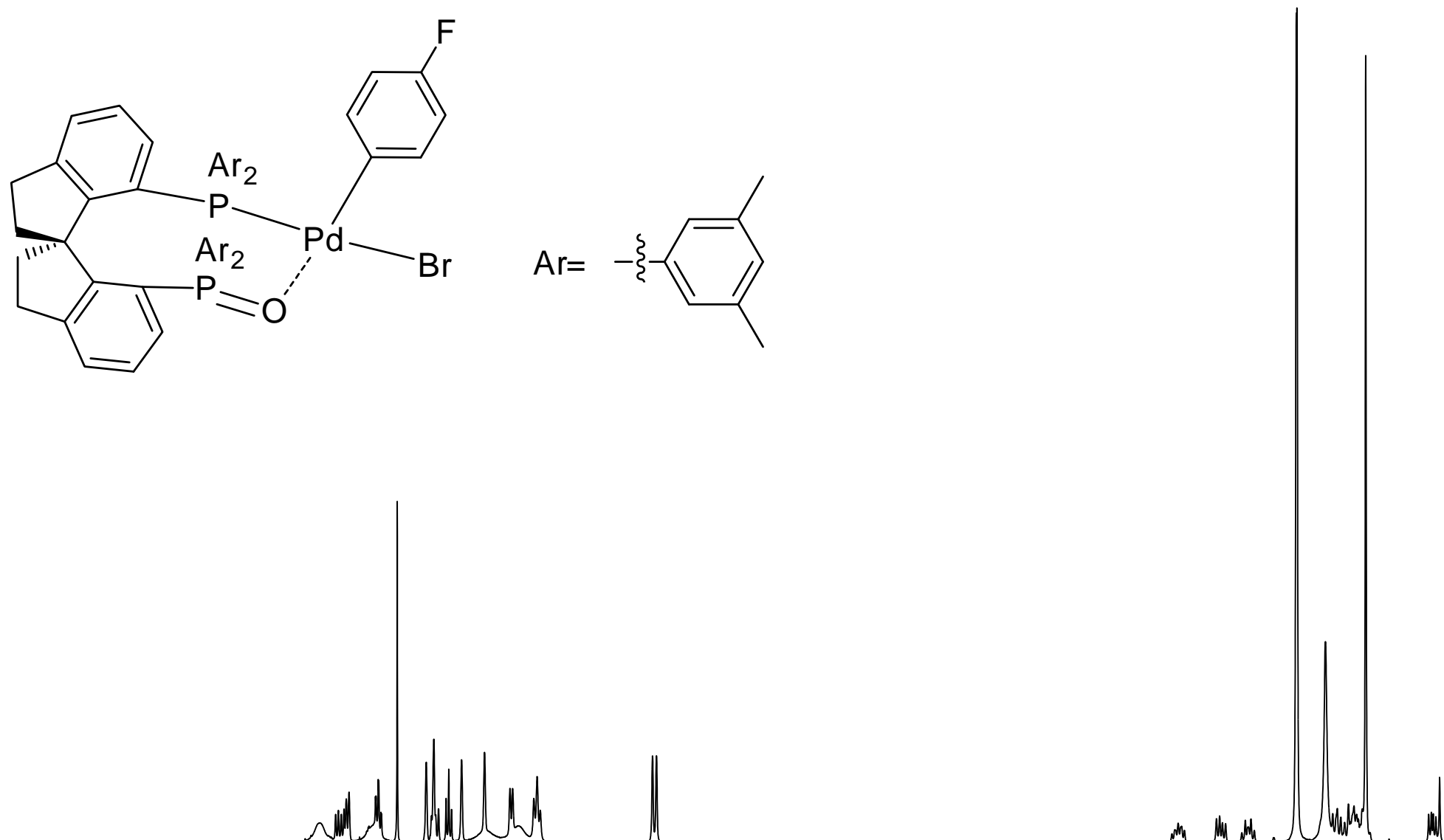

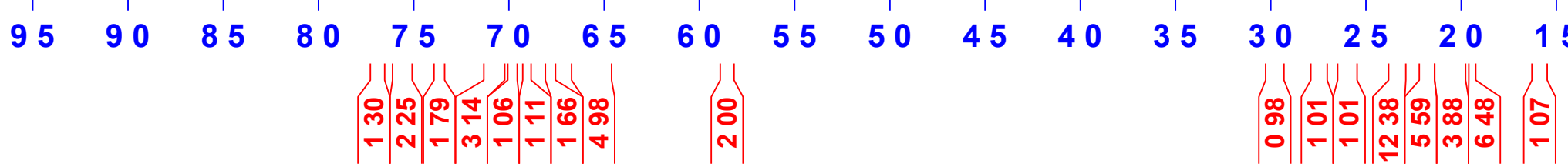


Complex-75 31P 1H AV500 13 Nov 2013

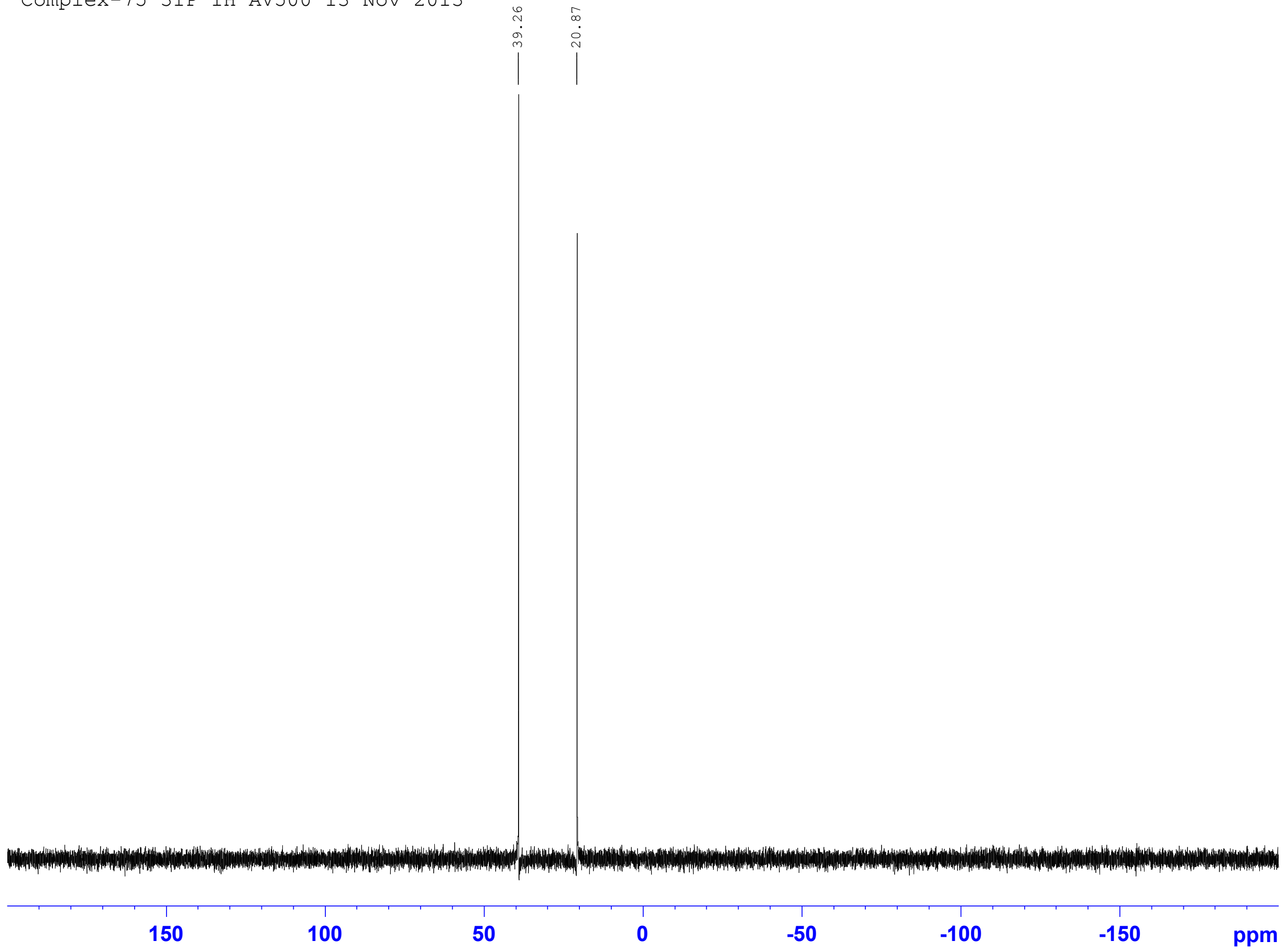


complex ,19F, BBFO1 400MHz, 22, Nov, 2013,

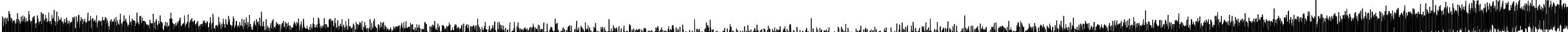

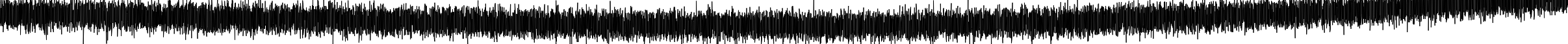

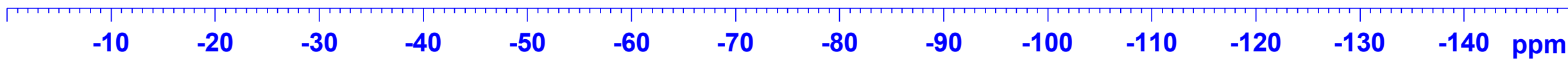

